\title{
An open randomized controlled trial of median sternotomy versus anterolateral left thoracotomy on morbidity and health care resource use in patients having off-pump coronary artery bypass surgery: The Sternotomy Versus Thoracotomy (STET) trial
}

\author{
Chris A. Rogers, PhD, ${ }^{a}$ Katie Pike, MSc, ${ }^{a}$ Gianni D. Angelini, FRCS, ${ }^{a}$ Barnaby C. Reeves, DPhil, ${ }^{\mathrm{a}}$ \\ Mattia Glauber, MD, ${ }^{\mathrm{b}}$ Matteo Ferrarini, MD, ${ }^{\mathrm{b}}$ and Gavin J. Murphy, FRCS ${ }^{\mathrm{a}}$
}

\begin{abstract}
Objective: Our objective was to compare off-pump coronary artery bypass surgery carried out via a left anterolateral thoracotomy (ThoraCAB) or via a conventional median sternotomy (OPCAB).
\end{abstract}

\begin{abstract}
Background: Recent advances in minimally invasive cardiac surgery have extended the technique to allow complete surgical revascularization on the beating heart via thoracotomy.
\end{abstract}

\begin{abstract}
Methods: Patients undergoing nonemergency primary surgery were enrolled between February 2007 and September 2009 at 2 centers. The primary outcome was the time from surgery to fitness for hospital discharge as defined by objective criteria.
\end{abstract}

\begin{abstract}
Results: A total of 93 patients were randomized to off-pump coronary artery bypass surgery via a median sternotomy (OPCAB) and 91 to off-pump coronary artery bypass surgery via a left anterolateral thoracotomy (ThoraCAB). The surgery was longer for patients in the ThoraCAB group (median, 4.1 vs 3.3 hours) and there were fewer with more than 3 grafts ( $2 \%$ vs $17 \%$ ). The median time from surgery to fitness for discharge was 6 days (interquartile range, 4-7) in the ThoraCAB group versus 5 days (interquartile range, 4-7) in the OPCAB group $(P=.53)$. The intubation time was shorter, by on average 65 minutes, in the ThoraCAB group $(P=.017)$, although the time in intensive care was similar $(P=.91)$. Pain scores were similar $(P=.97)$, but more analgesia was required in the ThoraCAB group (median duration, 38.8 vs 35.5 hours, $P<.001$; tramadol use, $66 \%$ vs $49 \%, P=.024)$. ThoraCAB was associated with significantly worse lung function at discharge (average difference, $-0.25 \mathrm{~L}, P=.01)$ but quality of life scores at 3 and 12 months were similar $(P=.52)$. The average total cost was $10 \%$ higher with ThoraCAB $(P=.007)$.
\end{abstract}

Conclusions: ThoraCAB resulted in no overall clinical benefit relative to OPCAB. (J Thorac Cardiovasc Surg 2013;146:306-16)

Supplemental material is available online.

\section{Earn CME credits at}

http://cme.ctsnetjournals.org

From the Bristol Heart Institute, ${ }^{\mathrm{a}}$ Bristol, United Kingdom; and the Cardiac Surgery Department, ${ }^{\mathrm{b}}$ Ospedale Pasquinucci, Massa Carrara, Italy.

Disclosures: The Garfield Weston Trust, London, United Kingdom; British Heart Foundation, London, United Kingdom, and National Institute for Health Research Bristol Biomedical Research Unit in Cardiovascular Medicine, Bristol, United Kingdom, supported this work. Authors have nothing to disclose with regard to commercial support.

Received for publication Dec 13, 2011; revisions received March 21, 2012; accepted for publication April 6, 2012; available ahead of print Sept 3, 2012.

Address for reprints: Gianni D. Angelini, FRCS, Bristol Heart Institute, Level 7, Queen's Building, University of Bristol, Bristol Royal Infirmary, Bristol BS2 8HW, United Kingdom (E-mail: G.D.Angelini@bristol.ac.uk).

$0022-5223 / \$ 36.00$

Copyright $(9) 2013$ by The American Association for Thoracic Surgery

http://dx.doi.org/10.1016/j.jtcvs.2012.04.020
Minimally invasive cardiac surgery (MICS) aims to reduce the inflammatory response, organ dysfunction, and morbidity attributable to surgical access, cardiopulmonary bypass (CPB), and manipulation of the aorta, while achieving complete revascularization. Minimally invasive direct coronary artery bypass (MIDCAB) via a left anterior small thoracotomy represented a milestone development, conferring the survival benefit of the left internal thoracic artery to the left anterior descending artery while avoiding sternotomy and $\mathrm{CPB} \cdot{ }^{1-3}$ The technique was then extended to patients with multivessel disease by combining MIDCAB with percutaneous coronary intervention to non-left anterior descending artery vessels to provide truly minimally invasive hybrid multivessel revascularization. ${ }^{4,5}$ However, hybrid procedures were only possible in selected patients with favorable anatomy. Moreover, logistical issues remained, and the reintervention rate was high. ${ }^{6-8}$ Rather, MIDCAB led to renewed interest in off-pump coronary artery bypass $(\mathrm{OPCAB})$ where complete revascularization could be achieved without CPB and often without aortic manipulation, albeit via a sternotomy incision. ${ }^{9,10}$ In 


\section{Abbreviations and Acronyms \\ $\mathrm{CABG}=$ coronary artery bypass graft \\ $\mathrm{CI}=$ confidence interval \\ $\mathrm{CPB}=$ cardiopulmonary bypass \\ $\mathrm{FEV}_{1}=$ forced expiratory volume after 1 second \\ FVC $=$ forced vital capacity \\ IL $\quad=$ interleukin \\ MICS = minimally invasive cardiac surgery \\ MIDCAB = minimally invasive direct coronary artery bypass \\ OPCAB = off-pump coronary artery bypass surgery via a median sternotomy \\ RCT $=$ randomized controlled trial \\ SIRS = systemic inflammatory response syndrome \\ ThoraCAB $=$ off-pump coronary artery bypass surgery via a left anterolateral thoracotomy \\ TR $=$ time ratio}

randomized controlled trials (RCTs), OPCAB reduced the inflammatory response and severity of organ injury and used fewer health care resources, ${ }^{11}$ with equivalent longterm graft patency, quality of life, and survival compared with coronary artery bypass grafting (CABG) with CPB. ${ }^{12,13}$

The increasingly high-risk population referred for surgery, the morbidity associated with sternotomy, economic considerations, and the desires of patients for less postoperative pain and a quicker return to normal living have led to pressure to further refine MICS techniques. To extend the advantages of OPCAB, several groups have developed a technique whereby complete revascularization may be performed on the beating heart through a lateral thoracotomy incision (ThoraCAB) with minimal morbidity and rapid hospital discharge. ${ }^{14-16}$ Concerns remain, however, as to whether in unselected patients technical precision may be compromised ${ }^{3}$ or whether excessive rib retraction may result in increased postoperative pain. ${ }^{17} \mathrm{We}$ carried out an RCT to evaluate whether ThoraCAB represents a clinical benefit beyond that conferred by OPCAB.

\section{METHODS}

\section{Study Design}

A 2-center, open, parallel-group RCT (ISRCTN 77366282) was used.

\section{Participants}

Participants included adults ( $>16$ years and $<80$ years) undergoing nonemergency primary $\mathrm{CABG}$ on the beating heart without the use of CPB and cardioplegic arrest. Patients who had undergone heart or lung surgery previously or for whom the surgeon was unwilling to carry out the surgery via either method were excluded.

\section{Study Settings}

The study was conducted at the Bristol Heart Institute, Bristol (United Kingdom) and Ospedale Pasquinucci, Massa Carrara (Italy), 2 specialized regional cardiac surgery centers. Three surgeons, 2 in Bristol and 1 in Italy, participated. The study was approved by the Southmead Research Ethics Committee (ref. 07/Q2002/53) and by the Comitato Etico Locale of the Ospedale Pasquinucci (protocol number 150).

\section{Interventions}

Patients were randomized to $\mathrm{CABG}$ on the beating heart through either a median sternotomy (OPCAB, control) or a left anterolateral thoracotomy (ThoraCAB, experimental). OPCAB was carried out as described previously ${ }^{9}$ with subsequent modifications subsumed into the current standard protocol, for example, use of an intracoronary shunt when performing a distal anastomosis. ThoraCAB, and associated anesthetic technique, was carried out as described by Guida and colleagues. ${ }^{14}$ With the left side of the patient elevated to approximately $30^{\circ}$, an anterolateral incision is made on the fourth or fifth intercostal space from the midclavicular to the anterior axillary line, sparing the latissimus dorsi. The left lung is usually deflated; if single lung ventilation is not possible, the left lung is gently compressed using a laparotomy sponge. The left internal thoracic artery is harvested under direct vision. The pericardium is incised from the pulmonary artery toward the ascending aorta and then toward the right atrial appendage. Traction sutures are positioned on the pericardium to rotate the ascending aorta to the right side. Proximal graft anastomoses on the aorta are performed first with a side-biting clamp in the conventional way. The pericardium is then incised parallel to the left phrenic nerve to expose the posterior and lateral wall vessels. Distal anastomoses are performed with an Octopus stabilizer (Medtronic Inc, Minneapolis, Minn) and intracoronary shunt.

Postoperative management was in accordance with institution-specific protocols. A protocol for postoperative pain relief for ThoraCAB patients was written by cardiac anesthetists and intensivists in Bristol. A policy of early extubation was adopted for all patients. For ThoraCAB patients, at the time of wound closure the surgeon sutured in place a paravertebral catheter to provide a paravertebral block (infusion of $0.125 \%$ bupivacaine, $5-10 \mathrm{~mL} / \mathrm{h}$ ); a 15 - to $20-\mathrm{mL}$ loading bolus of $0.25 \%$ bupivacaine through the catheter and injections into the intercostal spaces $(0.125 \%$ bupivacaine $)$ were also given before chest closure. Pain relief in the event of failure of the paravertebral catheter included the following: (1) local analgesia, intercostal blocks, up to 6 spaces injecting $5 \mathrm{~mL} 0.125 \%$ bupivacaine into each space, repeated 4 to 6 hourly if required; (2) adjuvant analgesia, intravenous ketoralac/diclofenac (up to $30 \mathrm{mg}$ ); (3) adjuvant analgesia, nurse administered intravenous morphine (up to 5-mg boluses); and (4) adjuvant analgesia, intravenous ketamine infusion $\left(1.5-3 \mu \mathrm{g} \cdot \mathrm{kg}^{-1} \cdot \mathrm{min}^{-1}\right)$. All patients had patient-controlled analgesia.

\section{Outcome Measures}

Primary outcome. The primary outcome was the number of days from surgery until fit for discharge from the hospital. Patients were classified fit when (1) the chest x-ray film was clear with no evidence of pleural effusion requiring drainage, lung collapse/consolidation, or pneumothorax, (2) there was no suspected infection, (3) routine blood test results and temperature were normal, and (4) the patient was physically fit.

The definition was modified partway through the trial after feedback from the independent Data Monitoring and Safety Committee. Initially, components 3 and 4 were not included. These data were collected retrospectively for the Bristol patients recruited before the change but were not available for the Italian patients. The definitions applied to minimize the susceptibility to detection bias are described in Appendix E1.

Secondary outcomes. Secondary outcomes were as follows: (1) the patient's judgment about his or her readiness for discharge; (2) biochemical inflammatory markers, that is, complement activation (C3a and C5) and interleukin (IL-6, IL-8, and IL-10) ${ }^{18}$ assessed preoperatively, at the end of the operation, and 4, 12, and 24 hours postoperatively; (3) pulmonary function 
tests at recruitment and discharge; (4) pain scores measured with a 10-cm visual analog scale at 2, 12, 24, and 36 hours after extubation and on discharge; (5) the total volume and dose of local anesthetic (paravertebral block), patient-controlled analgesia, and other intravenous analgesia administered; use of nonsteroidal anti-inflammatory or opioid drugs; (6) length of intensive care unit and postoperative hospital stay; (7) inhospital mortality and other standard measures of morbidity as used in previous RCTs ${ }^{9} ;(8)$ including ASEPSIS* at 6 weeks postoperatively ${ }^{19} ;(9)$ use of health care resources and associated costs; and (10) quality of life at recruitment and 3 and 12 months after surgery, measured using the coronary revascularization outcome questionnaire. ${ }^{20}$ Pulmonary function tests included peak expiratory flow rate, forced vital capacity (FVC), forced expiratory volume after 1 second $\left(\mathrm{FEV}_{1}\right)$ and the $\mathrm{FEV}_{1} / \mathrm{FVC}$ ratio. If a patient was unable to use the visual analog scale, a verbal response was requested.

Costs associated with health care resource use included staffing and overheads (1) in the theater for the duration of the operation, (2) during the intensive care, high dependency, and postoperative ward stay, (3) additional operative interventions to treat complications, and (4) readmissions. Costs were limited to the perspective of the United Kingdom National Health Service; information was not collected from participants (see Appendix E1).

Data on pulmonary function, postdischarge wound infections, and quality of life were collected for the Bristol patients only. Biochemical inflammatory markers were assessed in a consecutive subsample of 60 Bristol patients.

\section{Sample Size}

Inasmuch as no published data existed for time until fit for discharge, information about total postoperative hospital stay was used as a proxy. The 2 published case series for ThoraCAB reported $63 \%$ discharged within 4 days ${ }^{15}$ and $65 \%$ discharged within 2 days. ${ }^{14}$ The median postoperative stay after OPCAB in Bristol was 6 days, with $69 \%$ discharged within 7 days. We suspected that the ThoraCAB data were optimistic and so set the sample size to detect median times until fit for discharge of 3 and 5 days, respectively (assuming time until fit for discharge would be shorter, on average, than the total postoperative stay). A study of 180 patients (90 per group) had $90 \%$ power to detect this difference (hazard ratio, 1.65 ) with 5\% significance (2-tailed).

\section{Randomization}

Randomized treatment allocations were computer generated. ${ }^{21}$ Allocations were stratified by center and cohort minimization was used to ensure balance for the number of diseased vessels, diabetic status, and surgeon. Patients were assigned in a 1:1 ratio. The Internet-based system was password protected and allocations were concealed until data to uniquely identify the patient and confirm eligibility had been entered.

\section{Statistical Methods}

The time until fit for discharge was determined from the individual fitness criteria. A patient was classified fit on the earliest date after surgery when all the criteria were met (and no component event subsequently recurred before discharge). If any of the component events were not "resolved" during the patient's postoperative hospital stay (ie, the patient was discharged with 1 "event" or more present), then the patient's fitness was censored at the time of discharge from the cardiac unit. Similarly, if at least 1 of the criteria was not met before discharge and was not subsequently reassessed, then the outcome was censored at the time of this last assessment. For patients recruited in Italy before the fitness definition was changed, the actual length of postoperative hospital stay was used. If the time to extubation or discharge was not observed because the patient died, the outcome was censored at death.

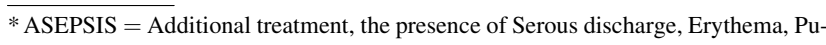
rulent exudate, and Separation of the deep tissues, the Isolation of bacteria, and the duration of inpatient Stay.
}

Analyses were carried out on the basis of intention to treat. Continuous variables were summarized using the mean and standard deviation (or median and interquartile range if the distribution was skewed), and categorical data were summarized as a number and percentage. All comparisons of outcomes between the OPCAB and ThoraCAB patients were adjusted for factors included in the cohort minimization. Results are presented as effect sizes with $95 \%$ confidence intervals (CIs).

One subgroup analysis, comparing the primary outcome for patients with and without pre-existing diabetes, was prespecified. This was examined by adding a diabetes-by-treatment interaction term to the model.

Sensitivity analyses were performed for the primary outcome (see Appendix E1).

Further detail on the statistical methodology used is given in Appendix E1.

\section{RESULTS \\ Patient Recruitment}

Patients were recruited from February 2007 to September 2009; 191 patients were enrolled, with 95 being allocated to ThoraCAB and 96 to OPCAB (Figure 1).

\section{Protocol Violations}

There were 20 protocol violations in 18 patients. Eight patients allocated to ThoraCAB had operations via OPCAB and 1 patient allocated to OPCAB had the operation via ThoraCAB. There were 11 conversions to on-pump surgery, 2 in the ThoraCAB group and 9 in the OPCAB group. Reasons for these protocol violations are given in Appendix E1. One patient, randomized to $\mathrm{OPCAB}$, withdrew 3 days after surgery but agreed to the data being used.

\section{Baseline Characteristics and Operative Details}

Patient demographics and operative characteristics are presented in Table 1 . The duration of surgery was, on average, 50 minutes longer for patients in the ThoraCAB group and fewer patients in the ThoraCAB group had more than 3 grafts.

\section{Numbers Analyzed}

Of the 191 patients enrolled, 184 were included in the analyses. Reasons for exclusion included the following: the surgery was postponed and they were subsequently transferred to a surgeon not participating in STET $(\mathrm{n}=2)$, additional left ventricular remodeling was required $(\mathrm{n}=2)$, and no trial data were submitted $(\mathrm{n}=3)$.

\section{Primary Outcome}

In the OPCAB group $77 \%$ of patients were classified as fit at or before hospital discharge compared with $68 \%$ in the ThoraCAB group. For the remaining patients the time to fitness was censored. The observed median time from surgery to fitness for discharge was 6 days (interquartile range, 4-7 days) in the ThoraCAB group versus 5 days (interquartile range, 4-7 days) in the OPCAB group. The estimated time ratio (TR; ThoraCAB/OPCAB) was $1.03(95 \% \mathrm{CI}$, $0.94-1.14 ; P=.53$ ), suggesting the time until fit for discharge was on average $3 \%$ longer in the ThoraCAB group. 


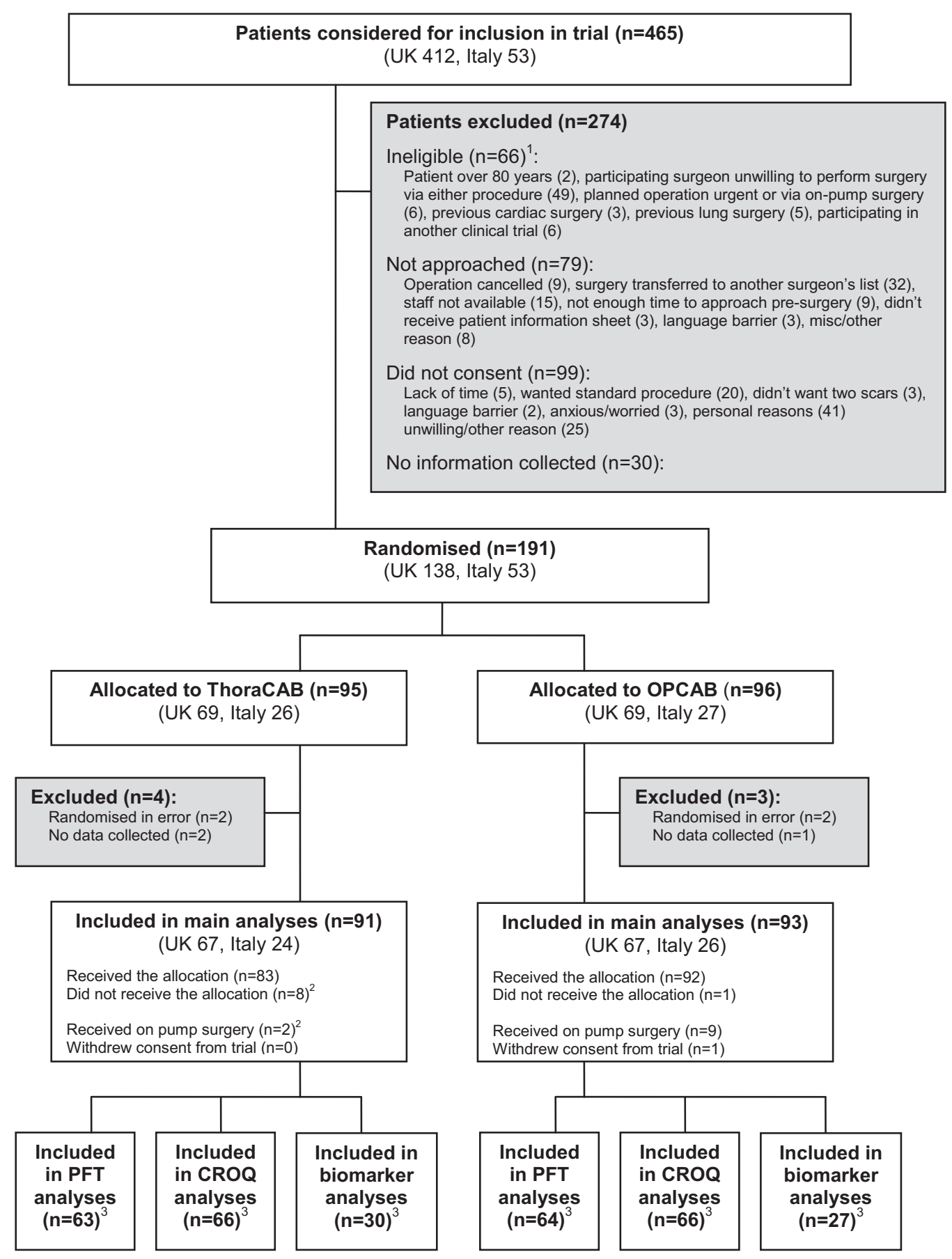

FIGURE 1. Flow diagram of the progress through the phases of the trial. Notes: (1) Some patients were ineligible for more than 1 reason. (2) The 2 patients who received on-pump surgery also did not receive their treatment allocation. (3) Only patients from the United Kingdom $(U K)$ are included in these cohorts. Thora $C A B$, Off-pump coronary artery bypass surgery via a left anterolateral thoracotomy; $O P C A B$, off-pump coronary artery bypass surgery via a median sternotomy; PFT, pulmonary function test; $C R O Q$, Coronary Revascularization Outcome Questionnaire

Figure $2, A$, shows the time to fitness for discharge by treatment group.

\section{Secondary Outcomes}

Postoperative clinical outcomes. Secondary clinical outcomes are reported in Table 2. The intubation time was shorter, by on average 65 minutes, for patients in the Thor$\mathrm{aCAB}$ group, although the time in intensive care and in the hospital was similar (Figure 2, $B$ and $C$ ) There were fewer arrhythmias in the ThoraCAB group, but other complications occurred with similar frequency. Total mediastinal fluid loss was on average $30 \%$ higher in the ThoraCAB 
TABLE 1. Patient demography, history, and operative data

\begin{tabular}{|c|c|c|c|c|c|c|}
\hline & \multicolumn{2}{|c|}{ Randomized to ThoraCAB $(n=91)$} & \multicolumn{2}{|c|}{ Randomized to OPCAB $(n=93)$} & \multicolumn{2}{|c|}{ Overall $(n=184)$} \\
\hline & $\mathbf{n}$ & $\%$ & $\mathbf{n}$ & $\%$ & $\mathbf{n}$ & $\%$ \\
\hline \multicolumn{7}{|l|}{ Demography } \\
\hline \multicolumn{7}{|l|}{ Age (y) } \\
\hline Mean (SD) & $63.1(8.7)$ & & $66.7(8.0)$ & & $64.9(8.5)$ & \\
\hline \multicolumn{7}{|l|}{ Sex } \\
\hline Male & 84 & 92 & 80 & 86 & 164 & 89 \\
\hline \multicolumn{7}{|l|}{ BMI } \\
\hline Mean (SD) & $27.6(4.1)$ & & $28.0(3.9) \ddagger$ & & $27.8(4.0)$ & \\
\hline \multicolumn{7}{|l|}{ Cardiac history } \\
\hline \multicolumn{7}{|l|}{ NYHA } \\
\hline I/asymptomatic & 48 & 53 & $44 \dagger$ & 48 & 92 & 51 \\
\hline II & 29 & 32 & 35 & 38 & 64 & 35 \\
\hline III & 12 & 13 & 10 & 11 & 22 & 12 \\
\hline IV & 2 & 2 & 2 & 2 & 4 & 2 \\
\hline \multicolumn{7}{|l|}{$\mathrm{CCS}$} \\
\hline No angina & 16 & 18 & $10 \dagger$ & 11 & 26 & 14 \\
\hline I & 16 & 18 & 14 & 15 & 30 & 16 \\
\hline II & 37 & 41 & 41 & 45 & 78 & 43 \\
\hline III & 18 & 20 & 17 & 19 & 35 & 19 \\
\hline IV & 4 & 4 & 9 & 10 & 13 & 7 \\
\hline Q-wave myocardial infarction & 27 & 30 & $26 \ddagger$ & 29 & 53 & 29 \\
\hline Congestive cardiac failure & 1 & 1 & $0 \dagger$ & 0 & 1 & 1 \\
\hline Concomitant valvular disease & 0 & 0 & $0 \dagger$ & 0 & 0 & 0 \\
\hline Other cardiac history & 7 & 8 & $0 \dagger$ & 0 & 7 & 4 \\
\hline \multicolumn{7}{|l|}{ Heart rhythm } \\
\hline Sinus & $89^{*}$ & 99 & $89^{*}$ & 97 & 178 & 98 \\
\hline Family history & 55 & 60 & $47 \S$ & 53 & 102 & 57 \\
\hline \multicolumn{7}{|l|}{ Left ventricular function } \\
\hline Good & $72 *$ & 80 & $69 \dagger$ & 76 & 141 & 78 \\
\hline Moderate & 17 & 19 & 18 & 20 & 35 & 19 \\
\hline Poor & 1 & 1 & 4 & 4 & 5 & 3 \\
\hline \multicolumn{7}{|l|}{ No. of vessels } \\
\hline Triple & 60 & 66 & 59 & 63 & 119 & 65 \\
\hline \multicolumn{7}{|l|}{ LMS disease } \\
\hline$>50 \%$ stenosis & $29^{*}$ & 32 & $43^{*}$ & 47 & 72 & 40 \\
\hline \multicolumn{7}{|l|}{ Euroscore } \\
\hline Median (IQR) & $3(1,4)^{*}$ & & $3(2,4) \|$ & & $3(2,4)$ & \\
\hline \multicolumn{7}{|l|}{ Noncardiac history } \\
\hline \multicolumn{7}{|l|}{ Smoking status } \\
\hline No & 36 & 40 & $35 \ddagger$ & 39 & 71 & 39 \\
\hline Ex-smoker $>1 \mathrm{mo}$ & 36 & 40 & 42 & 47 & 78 & 43 \\
\hline Yes & 19 & 21 & 13 & 14 & 32 & 18 \\
\hline Diabetes & 20 & 22 & 24 & 26 & 44 & 24 \\
\hline Hypertension & 66 & 73 & $75 \dagger$ & 82 & 141 & 77 \\
\hline Hypercholesterolemia & 77 & 85 & $72 \ddagger$ & 80 & 149 & 82 \\
\hline Hypothyroidism & 2 & 2 & $7 \S$ & 8 & 9 & 5 \\
\hline Peptic ulcer & 2 & 2 & $3 \ddagger$ & 3 & 5 & 3 \\
\hline CVA/TIAs & 4 & 4 & 2 & 2 & 6 & 3 \\
\hline Peripheral vascular disease & 2 & 2 & $6 \S$ & 7 & 8 & 4 \\
\hline Other medical condition & $35 \dagger$ & 39 & $27 \S$ & 30 & 62 & 35 \\
\hline \multicolumn{7}{|l|}{ Operative priority } \\
\hline Urgent & 20 & 22 & $28 \dagger$ & 31 & 48 & 26 \\
\hline
\end{tabular}




\begin{tabular}{|c|c|c|c|c|c|c|}
\hline & \multicolumn{2}{|c|}{ Randomized to ThoraCAB $(n=91)$} & \multicolumn{2}{|c|}{ Randomized to OPCAB $(n=93)$} & \multicolumn{2}{|c|}{ Overall $(n=184)$} \\
\hline & $\mathbf{n}$ & $\%$ & $\mathbf{n}$ & $\%$ & $\mathbf{n}$ & $\%$ \\
\hline \multicolumn{7}{|l|}{ Preoperative Tests } \\
\hline \multicolumn{7}{|l|}{ Creatinine $(\mu \mathrm{mol} / \mathrm{L})$} \\
\hline Mean (SD) & $92.9(18.5) \|$ & & $93.1(27.1) \S$ & & $93.0(23.2)$ & \\
\hline \multicolumn{7}{|l|}{ Hemoglobin $(\mathrm{g} / \mathrm{dL})$} \\
\hline Mean (SD) & $14.4(3.1) \dagger$ & & $13.9(1.5) \ddagger$ & & $14.1(2.5)$ & \\
\hline \multicolumn{7}{|l|}{ Platelets $\left(\times 10^{9} / \mathrm{L}\right)$} \\
\hline Mean (SD) & $236(62) \dagger$ & & $241(73) \ddagger$ & & $239(68)$ & \\
\hline \multicolumn{7}{|l|}{ Oxygen saturation $(\%)$} \\
\hline Median (IQR) & $97.0(96,98) \Phi$ & & $97.5(96,98) \Phi$ & & $97(96,98)$ & \\
\hline \multicolumn{7}{|l|}{ Mobility } \\
\hline Able to walk $70 \mathrm{~m}$ & $68 \#$ & 99 & $64 \#$ & 89 & 132 & 94 \\
\hline \multicolumn{7}{|l|}{ Drugs on admission } \\
\hline Diuretics & $19 \dagger$ & 21 & $14 \dagger$ & 15 & 33 & 18 \\
\hline Beta-blockers & 75 & 82 & $66 \dagger$ & 73 & 141 & 77 \\
\hline Calcium antagonists & $36 \ddagger$ & 41 & $36 \dagger$ & 40 & 72 & 40 \\
\hline Oral nitrates & 16 & 18 & $18 \ddagger$ & 20 & 34 & 19 \\
\hline Heparin until operation & 22 & 24 & $25 \dagger$ & 27 & 47 & 26 \\
\hline ACE inhibitor & 58 & 64 & $55 \dagger$ & 60 & 113 & 62 \\
\hline Statins & 81 & 89 & $79 \dagger$ & 87 & 160 & 88 \\
\hline Aspirin & 75 & 82 & $83 \ddagger$ & 92 & 158 & 87 \\
\hline \multicolumn{7}{|l|}{ Days preoperative aspirin stopped } \\
\hline Median (IQR) & $3(1,6)^{*}$ & & $2(1,5)$ & & $3(1,5)$ & \\
\hline Clopidogrel & 18 & 20 & $22 \dagger$ & 24 & 40 & 22 \\
\hline \multicolumn{7}{|l|}{ Days preoperative clopidogrel stopped } \\
\hline Median (IQR) & $8(6,11)$ & & $7(3,8)$ & & $7(5,10.5)$ & \\
\hline Other drugs & $45^{*}$ & 50 & $52 \dagger$ & 57 & 97 & 54 \\
\hline \multicolumn{7}{|l|}{ Operative data in theater } \\
\hline \multicolumn{7}{|l|}{ Operation duration (h) } \\
\hline Median (IQR) & $4.1(3.5,4.7)$ & & $3.3(3.0,4.0)$ & & $3.7(3.2,4.5)$ & \\
\hline \multicolumn{7}{|l|}{ No. of grafts } \\
\hline 1 & $3 \ddagger$ & 3 & $4 *$ & 4 & 7 & 4 \\
\hline 2 & 41 & 47 & 41 & 45 & 82 & 46 \\
\hline 3 & 42 & 48 & 31 & 34 & 73 & 41 \\
\hline$>3$ & 2 & 2 & 16 & 17 & 18 & 10 \\
\hline \multicolumn{7}{|l|}{ Lowest core temperature $\left({ }^{\circ} \mathrm{C}\right)$} \\
\hline Mean (SD) & $35.3(0.61)$ & & $35.1(0.83) \dagger$ & & $35.2(0.73)$ & \\
\hline \multicolumn{7}{|l|}{ Lowest hematocrit $(\%)$} \\
\hline Mean (SD) & $35.9(4.5) \dagger$ & & $34.1(5.8) \dagger$ & & $35.0(5.3)$ & \\
\hline Tranexamic acid & 72 & 79 & $73 \dagger$ & 80 & 145 & 80 \\
\hline Cell salvage & 54 & 59 & $43 \ddagger$ & 48 & 97 & 54 \\
\hline Red blood cell transfusion** & 0 & 0 & $2 \dagger$ & 2 & 2 & 1 \\
\hline Other blood products $\dagger \dagger$ & 1 & 1 & $0 \dagger$ & 0 & 1 & 1 \\
\hline Arrythmias on chest closure $\ddagger \ddagger$ & $2 \dagger$ & 2 & $1 \ddagger$ & 1 & 3 & 2 \\
\hline Defibrillation & 4 & 4 & $3 \dagger$ & 3 & 7 & 4 \\
\hline Pacing & 1 & 1 & $0 \dagger$ & 0 & 1 & 1 \\
\hline Inotropes (including norepinephrine) & 3 & 3 & $5 \dagger$ & 5 & 8 & 4 \\
\hline Vasodilators & 7 & 8 & $21 \dagger$ & 23 & 28 & 15 \\
\hline IABP & 1 & 1 & $1 \dagger$ & 1 & 2 & 1 \\
\hline \multirow{2}{*}{\multicolumn{7}{|c|}{$\begin{array}{l}\text { On return to intensive care unit } \\
\text { Temperature }\left({ }^{\circ} \mathrm{C}\right)\end{array}$}} \\
\hline & & & & & & \\
\hline Mean (SD) & $35.9(0.96)$ & & $35.7(0.74)$ & & $35.8(0.86)$ & \\
\hline
\end{tabular}


TABLE 1. Continued

\begin{tabular}{|c|c|c|c|c|c|c|}
\hline & \multicolumn{2}{|c|}{ Randomized to ThoraCAB $(\mathrm{n}=91)$} & \multicolumn{2}{|c|}{ Randomized to OPCAB $(n=93)$} & \multicolumn{2}{|c|}{ Overall $(n=184)$} \\
\hline & $\mathbf{n}$ & $\%$ & $\mathbf{n}$ & $\%$ & $\mathbf{n}$ & $\%$ \\
\hline \multicolumn{7}{|l|}{ Hematocrit $(\%)$} \\
\hline Mean (SD) & $35.6(4.9)$ & & $32.3(4.4)^{*}$ & & $33.9(4.9)$ & \\
\hline \multicolumn{7}{|l|}{ Lactate $(\mathrm{mmol} / \mathrm{L})$} \\
\hline Median (IQR) & $1.1(0.9,1.5)$ & & $1.3(1.0,1.7)^{*}$ & & $1.2(0.9,1.6)$ & \\
\hline \multicolumn{7}{|c|}{ First 24 hours postoperatively } \\
\hline \multicolumn{7}{|c|}{ Nadir hemoglobin (g/dL) } \\
\hline Mean (SD) & $11.3(1.5)$ & & $10.7(2.1) \dagger$ & & $11.0(1.8)$ & \\
\hline \multicolumn{7}{|c|}{ Nadir hematocrit $(\%)$} \\
\hline Mean (SD) & $33.7(4.6)$ & & $31.2(4.5)$ & & $32.4(4.7)$ & \\
\hline \multicolumn{7}{|c|}{ Nadir MABP (mm Hg) } \\
\hline Mean (SD) & $64.7(12.4)$ & & $64.2(11.3)$ & & $64.5(11.8)$ & \\
\hline \multicolumn{7}{|c|}{ Highest lactate (mmol/L) } \\
\hline Median (IQR) & $1.8(1.4,2.4)$ & & $1.9(1.4,2.5)$ & & $1.8(1.4,2.5)$ & \\
\hline
\end{tabular}

Thora $C A B$, Off-pump coronary artery bypass surgery via a left anterolateral thoracotomy; $O P C A B$, off-pump coronary artery bypass surgery via a median sternotomy; $S D$, standard deviation; BMI, body mass index; NYHA, New York Heart Association; CCS, Canadian Cardiovascular Society; LMS, left main stem; IQR, interquartile range; CVA, cerebrovascular accident; TIA, transient ischemic attack; $A C E$, angiotensin-converting enzyme; IABP, intra-aortic balloon pump; $M A B P$, mean arterial blood pressure. $*$ One patient with missing data. †Two patients with missing data. †Three patients with missing data. §Four patients with missing data. $\|$ Five patients with missing data. $₫$ Missing for 65 in ThoraCAB group and 63 in OPCAB group (not collected for earlier part of trial). \#Missing for 22 in ThoraCAB group and 21 in OPCAB group (not collected at Italian center for earlier part of trial). **Both patients received 2 units. ††One patient received fresh frozen plasma ( 2 units). $\ddagger \ddagger$ All arrhythmias were atrial fibrillation.

group. This was related to the paravertebral block inasmuch as drainage invariably stopped once the anesthetic infusion was discontinued.

Adverse events. The frequencies of adverse events were similar in the 2 groups (Tables E1-E3). There were 2 deaths in the OPCAB group after discharge from the hospital. There were 2 unexpected serious adverse events in patients given ThoraCAB, which were classified as related to the trial intervention. These were a left heart hernia through the thoracotomy wound requiring repair (definitely related) and an acute type A aortic dissection (probably related).

Pain relief and pain scores. On average, the duration of patient-controlled analgesia was 37\% longer for patients in the ThoraCAB group, but the total administered dose was similar (Table 2). Complications related to paravertebral block were rare (11 cases, Table E4). Pain scores reduced over time and were similar in the 2 groups (Table 2). Pulmonary function tests. At hospital discharge, both the mean $\mathrm{FEV}_{1}$ and mean FVC were higher in the OPCAB group, but the peak expiratory flow and $\mathrm{FEV}_{1} / \mathrm{FVC}$ ratio were similar (Table 3).

Biochemical inflammatory markers. For IL-6, lower average concentrations in the ThoraCAB group were observed at 4 hours (ratio, $0.72 ; 95 \% \mathrm{CI}, 0.53-0.99 ; P=.05$ ), but at other time points the response was similar. For IL- 8 , the response was, on average, $18 \%$ lower in the ThoraCAB group (ratio, 0.82; 95\% CI, 0.68-0.99; $P=.044$ ) while for IL-10 and C5a the response was similar (ratio, 1.04; 95\% CI, $0.80-1.35 ; P=.77$; and ratio, $1.09 ; 95 \% \mathrm{CI}, 0.97-1.22$; $P=.12$, respectively). For C3a, the treatment effect varied with time, but there was no significant difference between the groups at any individual time point (Table E5).
Hospital resource use and costs. On average, the cost of ThoraCAB was approximately $10 \%$ higher than the cost of OPCAB (ratio, 1.10; 95\% CI, 1.02-1.18; $P=.007$; Table E6). This was due to longer operation times, more reoperations, and the higher cost of hospital readmissions.

Quality of life scores. On all scales (core total centred on 50 with an SD of 10; scores for all other dimensions scaled from 0 to 100), higher scores indicated better quality of life. Scores did not differ significantly between the groups and there was no evidence of treatment-by-time interactions (Table E7). The average difference in core total score between the ThoraCAB and OPCAB groups was -0.47 (95\% CI, -1.94 to $0.99 ; P=.52)$.

\section{Sensitivity Analyses of Time Until Fit for Discharge}

The sensitivity analyses did not alter the conclusion (see Appendix E1).

\section{Subgroup Analysis of Fitness for Discharge}

The data suggested a potentially greater treatment difference in favor of OPCAB for the subgroup with pre-existing diabetes (TR, 1.19; 95\% CI, 0.97-1.46; $P=.093$ ) than for the nondiabetic subgroup (TR, 0.99; 95\% CI, 0.89-1.11; $P=.86)$, but the interaction of diabetes with treatment was not statistically significant $(P=.12)$.

\section{DISCUSSION \\ Main Findings}

In this 2-center RCT, ThoraCAB was not associated with a reduced time until fit for hospital discharge relative to OP$\mathrm{CAB}$. The benefits of ThoraCAB, including reduced levels of proinflammatory cytokines, earlier extubation, and fewer postoperative arrhythmias, were offset by longer operation 

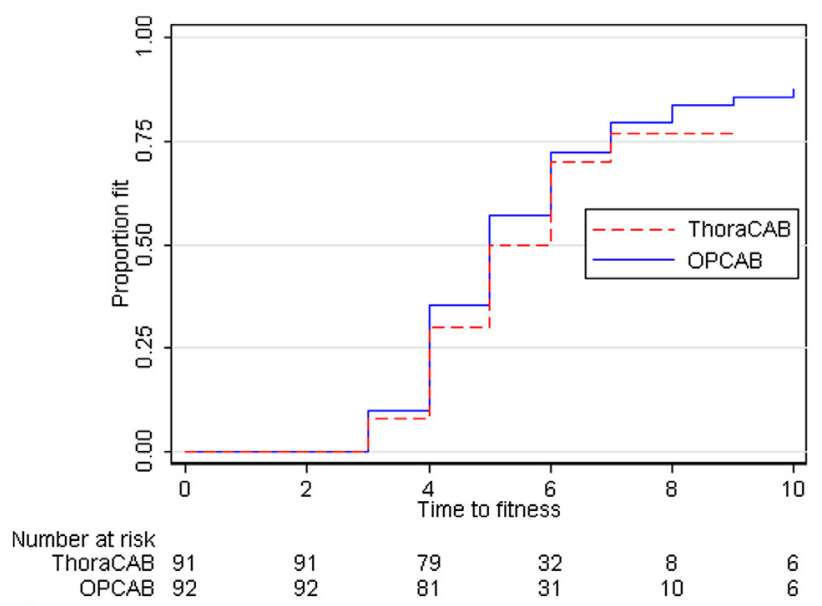

A
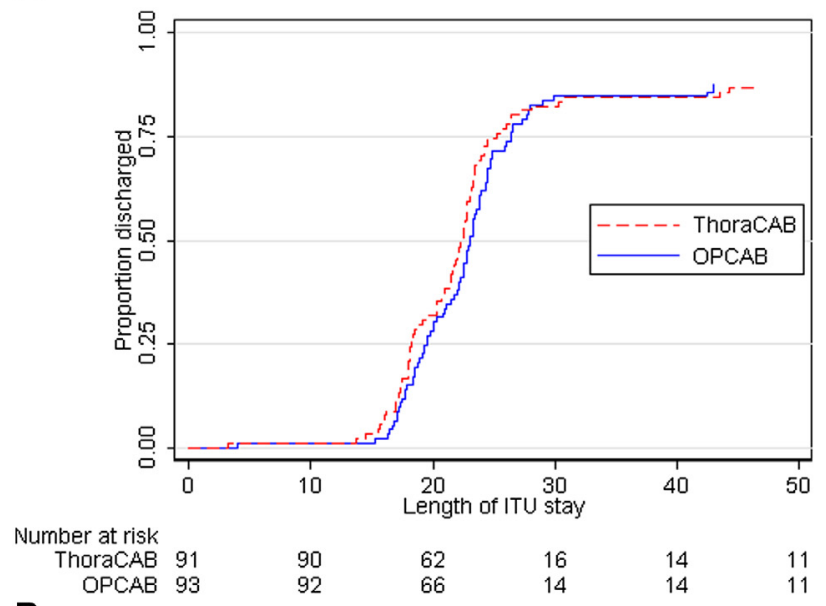

B

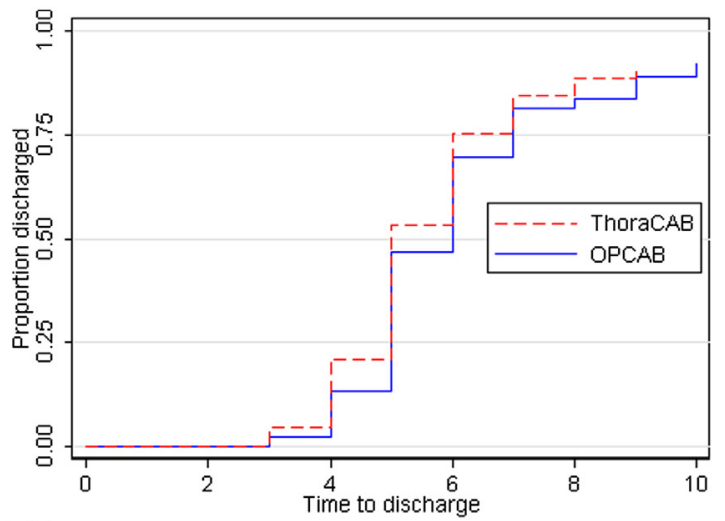

Number at risk

$\begin{array}{lllllll}\text { ThoraCAB } & 91 & 91 & 87 & 42 & 14 & 7\end{array}$

C

OPCAB 92

92

90

17

7

FIGURE 2. Time from surgery to (A) fitness for discharge, (B) discharge from intensive treatment unit (ITU), and (C) discharge from hospital. Thor$a C A B$, Off-pump coronary artery bypass surgery via a left anterolateral thoracotomy; $O P C A B$, off-pump coronary artery bypass surgery via a median sternotomy.

times, fewer distal anastomoses on average, greater analgesia requirements, significantly worse lung function at discharge, a higher reoperation rate (4 vs 0 cases), and increased cost. The only in-hospital death was also in the ThoraCAB group. The benefits previously reported with ThoraCAB in observational studies were not replicated in STET, but patients in the 2 groups had comparable quality of life at 12 months, and our data suggest that ThoraCAB is not obviously unsafe or inferior to OPCAB.

\section{Limitations}

The relatively small study size with only 3 surgeons participating represents a potential limitation. The study was powered to detect a 2-day difference in the primary outcome; it was not powered to detect the smaller difference observed, nor was it powered to detect differences in secondary outcomes. Only 1 OPCAB patient had a deep sternal wound infection, which was consistent with the reported $0.88 \%$ incidence rate, ${ }^{22}$ so that one of the main proposed benefits of avoiding sternotomy was not evident. Such a benefit may be detected by a larger study or in a cohort at greater risk for sternal infection, but this was not supported by our data, which suggested a potentially greater difference in recovery time in favor of $O P C A B$ for the patients with pre-existing diabetes. In addition, our results are unlikely to be altered substantially by a larger study because ThoraCAB had both advantages and disadvantages. Also, reductions in markers of the inflammatory response, a major determinant of postoperative outcome, were relatively small. The $18 \%$ reduction in IL- 8 with ThoraCAB contrasts with an approximate $40 \%$ reduction observed in trials of OPCAB versus $\mathrm{CABG}$ with $\mathrm{CPB},{ }^{18}$ where modest reductions in morbidity and resource use were evident.

The lack of masking was unavoidable but represents another limitation. To overcome this we adopted a definition of recovery based on objective criteria commonly used in making discharge decisions. A significant proportion of patients were discharged before all the criteria were met, and this was most prevalent in the ThoraCAB group, where the median postoperative hospital stay was shorter. This suggests either a possible bias on the part of attending clinicians or that the criteria used may not have adequately characterized clinicians' decisions. However, our conclusion that there was no difference in time to recovery or to discharge was supported by the majority of patients in both groups that believed the discharge decision was "about right."

The change to our definition of the primary end point part way through the trial is also a limitation. However, we do not believe that our imputation using time to hospital discharge for the Italian patients, for whom the additional data could not be retrieved retrospectively, biases our findings inasmuch as our conclusion was unchanged when these patients were excluded in a sensitivity analysis.

\section{Resource Use}

ThoraCAB patients were extubated earlier, an advantage observed to a greater extent in other series ${ }^{14}$ but this did not 
TABLE 2. Secondary clinical outcomes

\begin{tabular}{|c|c|c|c|c|c|c|}
\hline & \multicolumn{2}{|c|}{$\begin{array}{c}\text { Randomized to } \\
\text { ThoraCAB }(n=91) \\
\end{array}$} & \multicolumn{2}{|c|}{$\begin{array}{c}\text { Randomized to } \\
\text { OPCAB }(n=93)\end{array}$} & \multirow[b]{2}{*}{ Effect $(95 \%$ CI $)$} & \multirow{2}{*}{$\begin{array}{c}P \\
\text { value }\end{array}$} \\
\hline & n & $\%$ & n & $\%$ & & \\
\hline \multicolumn{7}{|l|}{ Length of hospital stay (d)* } \\
\hline Median (IQR) & $5(5,6)$ & & $6(5,7)$ & & TR $0.94(0.86,1.02)$ & .16 \\
\hline \multicolumn{7}{|l|}{ Length of intensive care unit stay (h) } \\
\hline Median (IQR) & $22.4(18.2,25.2)$ & & $23.0(19.5,26.4)$ & & HR $0.98(0.73,1.33)$ & .91 \\
\hline \multicolumn{7}{|l|}{ Intubation time $(\mathrm{min}) *$} \\
\hline Median (IQR) & $256(115,464)$ & & $321(194,509)$ & & TR $0.75(0.60,0.95)$ & .017 \\
\hline Death in hospital & 1 & 1 & 0 & 0 & & \\
\hline \multicolumn{7}{|c|}{ Participants' judgment about readiness for discharge $\dagger$} \\
\hline Too soon & 1 & 1 & 1 & 1 & OR $0.53(0.22,1.30)$ & .16 \\
\hline About right & 69 & 82 & 64 & 76 & & \\
\hline Could have been earlier & 9 & 11 & 17 & 20 & & \\
\hline Not sure & 5 & 6 & 2 & 2 & & \\
\hline Perioperative myocardial infarction $\ddagger$ & 4 & 4 & 1 & 1 & & \\
\hline Cardiac arrest $\S$ & 0 & 0 & 0 & 0 & & \\
\hline Hemodyamic support & 40 & 44 & 36 & 39 & OR $1.28(0.67,2.43)$ & .45 \\
\hline Arrhythmias $\S$ & 21 & 23 & 32 & 35 & OR $0.52(0.26,1.03)$ & .059 \\
\hline Pulmonary complications $\S$ & 13 & 14 & 9 & 10 & OR $1.56(0.62,3.90)$ & .34 \\
\hline Renal complications $\S$ & 0 & 0 & 0 & 0 & & \\
\hline Infective complications $\|$ & 10 & 11 & 10 & 11 & OR $1.02(0.40,2.58)$ & .97 \\
\hline Gastrointestinal complications $\S$ & 2 & 2 & 1 & 1 & & \\
\hline Neurologic complications§ & 1 & 1 & 1 & 1 & & \\
\hline Reoperation & 4 & 4 & 0 & 0 & & \\
\hline \multicolumn{7}{|l|}{ Blood loss in first 12 hours\# } \\
\hline GM & 449 & & 404 & & GMR $1.10(0.97,1.26)$ & .13 \\
\hline \multicolumn{7}{|l|}{ Total mediastinal fluid loss** } \\
\hline GM & 856 & & 649 & & GMR $1.31(1.15,1.49)$ & $<.001$ \\
\hline Red blood cell transfusion after surgery $\dagger \dagger$ & 7 & 8 & 12 & 13 & OR $0.55(0.20,1.51)$ & .24 \\
\hline \multicolumn{7}{|l|}{ If yes, units transfused } \\
\hline Median (IQR) & $3(1,3)$ & & $2(1,3)$ & & & \\
\hline Other transfusion after surgery $\ddagger \ddagger$ & 5 & 5 & 2 & 2 & & \\
\hline Activated factor VII used after surgery?§§ & 0 & 0 & 0 & 0 & & \\
\hline \multicolumn{7}{|l|}{ Asepsis score $>20$ (any wound) } \\
\hline Before discharge & 0 & 0 & 1 & 1 & & \\
\hline Six weeks after discharge \|\|$\|$ & 8 & 13 & 7 & 11 & OR $1.16(0.40,3.41)$ & .78 \\
\hline \multicolumn{7}{|l|}{ Pain relief } \\
\hline \multicolumn{7}{|l|}{ PCA duration $(\mathrm{h}) \dagger \dagger$} \\
\hline Median (IQR) & $38.8(32.5,47.2)$ & & $35.5(24.8,40.2)$ & & TR $1.37(1.25,1.49)$ & $<.0001$ \\
\hline \multicolumn{7}{|l|}{ PCA volume (mg) $\S \S \S$} \\
\hline GM & 50.9 & & 48.2 & & GMR $1.04(0.86,1.24)$ & .69 \\
\hline Use of NSAIDs $\ddagger \ddagger \dagger$ & 16 & 18 & 9 & 10 & OR $2.18(0.89,5.36)$ & .082 \\
\hline Use of tramadol§ & 57 & 66 & 45 & 49 & OR $2.53(1.11,5.76)$ & .024 \\
\hline Use of codeine (or similar) ||| & 11 & 13 & 9 & 10 & OR $1.28(0.49,3.36)$ & .61 \\
\hline Pain scores $\llbracket \rrbracket$ & $(\mathrm{n}=84)$ & & $(\mathrm{n}=89)$ & & & \\
\hline \multicolumn{7}{|l|}{ Two hours after extubation\#\# } \\
\hline Mean (SE) & 35.0 & 2.50 & 35.0 & 2.52 & & \\
\hline \multicolumn{7}{|l|}{ Twelve hours after extubation $* * *$} \\
\hline Mean (SE) & 30.1 & 1.76 & 30.2 & 1.78 & & \\
\hline \multicolumn{7}{|l|}{ Twenty-four hours after extubation $\dagger \dagger \dagger$} \\
\hline Mean (SE) & 27.1 & 1.63 & 27.2 & 1.66 & & \\
\hline \multicolumn{7}{|l|}{ 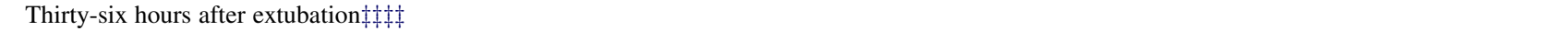 } \\
\hline Mean (SE) & 25.1 & 1.56 & 25.1 & 1.59 & & \\
\hline
\end{tabular}




\begin{tabular}{|c|c|c|c|c|c|c|}
\hline & \multicolumn{2}{|c|}{$\begin{array}{c}\text { Randomized to } \\
\text { ThoraCAB }(n=91)\end{array}$} & \multicolumn{2}{|c|}{$\begin{array}{c}\text { Randomized to } \\
\text { OPCAB }(n=93)\end{array}$} & \multirow[b]{2}{*}{ Effect $(95 \% \mathrm{CI})$} & \multirow{2}{*}{$\begin{array}{c}P \\
\text { value }\end{array}$} \\
\hline & $\mathbf{n}$ & $\%$ & $\mathbf{n}$ & $\%$ & & \\
\hline \multicolumn{7}{|l|}{ Five days after extubation $\S \S \S \S$} \\
\hline Mean (SE) & 17.8 & 1.73 & 17.8 & 1.75 & & \\
\hline Test for treatment time interaction & & & & & & .67 \\
\hline Overall estimate of treatment effect & & & & & $-0.063(-3.85,3.72)$ & .97 \\
\hline
\end{tabular}

Thora $C A B$, Off-pump coronary artery bypass surgery via a left anterolateral thoracotomy; $O P C A B$, off-pump coronary artery bypass surgery via a median sternotomy; $C I$, confidence interval; $I Q R$, interquartile range; $T R$, time ratio; $H R$, hazard ratio; $O R$, odds ratio; $G M$, geometric mean; GMR, geometric mean ratio; $P C A$, patient-controlled analgesia; NSAIDs, nonsteroidal anti-inflammatory drugs; SE, standard error. *One outlier was excluded (OPCAB group). †Comparison is "could have been earlier" versus "too soon"/ "about right." The most commonly occurring category ("about right") was imputed for the 16 patients (7 ThoraCAB group, 9 OPCAB group) with missing data. The same treatment estimate and $P$ value were obtained in a model without imputing missing data. $\ddagger$ Defined as troponin $\mathrm{I}>0.5 \mu \mathrm{g} / \mathrm{L}$ and at least 1 of the following: $(1)$ new Qs in 2 contiguous leads, (2) new ST depression $>2 \mathrm{~mm}$ in 2 leads. One patient (OPCAB group) with missing data. $§$ One patient (OPCAB group) with missing data. $\|$ Adjustment for surgeon or center caused perfect prediction. Only diabetes and number of diseased vessels were adjusted for. 9 All reoperations occurred in the first 24 hours after surgery and were for bleeding. Two patients (OPCAB group) with missing data. \#One outlier was excluded (ThoraCAB group). **One outlier was excluded (ThoraCAB group). Three patients (1 ThoraCAB group, 2 OPCAB group) with missing data. $\dagger \dagger$ Two patients (OPCAB group) with missing data. $\ddagger \ddagger$ Other transfusions consist of the following: ThoraCAB group: platelets $(\mathrm{n}=4)$, cryoprecipitate $(\mathrm{n}=1)$; OPCAB group: fresh frozen plasma $(\mathrm{n}=1)$, fresh frozen plasma and platelets $(\mathrm{n}=1)$. Two patients $(\mathrm{OPCAB}$ group $)$ with missing data. $\S \S$ Two patients (ThoraCAB group) with missing data. ||||Data only collected for Bristol patients. Asepsis score $\leq 20$ (most common category) was imputed for the 12 Bristol patients (6

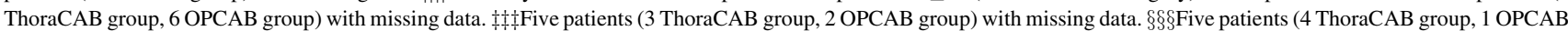
group) with missing data. |||Seven patients (4 ThoraCAB group, 3 OPCAB group) with missing data. 9 ๆThirteen patients had one score collected, 7 patients had two scores, 23 had three scores, 54 had four scores, and 74 had five scores. Method of pain assessment was missing for 25 observations (3.7\%) on 19 individuals. The most common group (verbal) was imputed for these observations. \#\#Forty-six patients (19 ThoraCAB group, 27 OPCAB group) with missing data, including 25 patients recorded as asleep (10 ThoraCAB group, 15 OPCAB group). ***Twenty-eight patients (11 ThoraCAB group, 17 OPCAB group) with missing data, including 10 patients recorded as asleep (4 ThoraCAB group, 6 OPCAB group). †† Twenty-nine patients (9 ThoraCAB group, 20 OPCAB group) with missing data, including 7 patients recorded as asleep (3 ThoraCAB group, 4

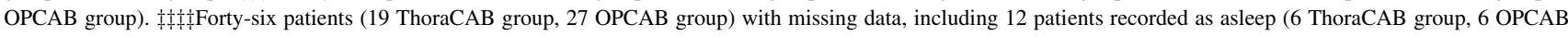
group). $\S \S \S \S$ Estimates are provided at 5 days after extubation (approximate median time discharge score was done). Twenty-four patients (11 ThoraCAB group, 13 OPCAB group) with missing data. No patients were recorded as asleep.

translate into a benefit over OPCAB. This could be because (1) previous observational reports did not compare contemporaneous cohorts, ${ }^{14-16}$ (2) the rapid discharge protocol advocated in these studies was not applicable to this cohort that was, on average, 10 years older, ${ }^{14}$ (3) changing other clinicians' practice to extubate early was difficult and the average time to extubation was only reduced by approximately 1 hour, which is of limited clinical significance; and (4) patient transfer to less intensive levels of care was determined by institutional protocols that are influenced by postoperative organ dysfunction and nursing requirements.

\section{Adequacy of Revascularization}

A risk attendant to the use of MIDCAB techniques is that as invasiveness declines so too does the completeness of revascularization. Fewer grafts were performed in the ThoraCAB group despite the 2 groups being well matched in the

TABLE 3. Pulmonary function

\begin{tabular}{|c|c|c|c|c|c|c|}
\hline \multirow[b]{2}{*}{ Baseline } & \multicolumn{2}{|c|}{$\begin{array}{c}\text { Randomized to } \\
\text { ThoraCAB }(n=63)\end{array}$} & \multicolumn{2}{|c|}{$\begin{array}{c}\text { Randomized to } \\
\text { OPCAB }(n=64)\end{array}$} & \multirow[t]{2}{*}{$\begin{array}{c}\text { Mean difference } \\
\text { (ThoraCAB-OPCAB) } \\
(95 \% \text { CI }) \\
\end{array}$} & \multirow[t]{2}{*}{$P$ value } \\
\hline & Mean & SD & Mean & SD & & \\
\hline $\mathrm{FEV}_{1}(\mathrm{~L})^{*}$ & 2.84 & 0.69 & 2.48 & 0.73 & & \\
\hline $\mathrm{FVC}(\mathrm{L}) \dagger$ & 3.56 & 0.76 & 3.22 & 0.88 & & \\
\hline $\operatorname{PEF}(\mathrm{L} / \mathrm{m}) \ddagger$ & 379 & 135 & 371 & 140 & & \\
\hline $\mathrm{FEV}_{1} / \mathrm{FVC}$ ratio $(\%) \S$ & 78.9 & & 76.2 & & & \\
\hline Discharge & Mean & SE & Mean & SE & & \\
\hline $\mathrm{FEV}_{1}(\mathrm{~L}) \|$ & 1.48 & 0.10 & 1.61 & 0.09 & $-0.13(-0.28,0.02)$ & .09 \\
\hline $\mathrm{FVC}(\mathrm{L}) \|$ & 1.90 & 0.11 & 2.15 & 0.11 & $-0.25(-0.44,-0.06)$ & .01 \\
\hline $\operatorname{PEF}(\mathrm{L} / \mathrm{m}) \|$ & 229 & 21 & 255 & 21 & $-26(-62,11)$ & .17 \\
\hline $\mathrm{FEV}_{1} / \mathrm{FVC}$ ratio $(\%)$ & 78.8 & & 77.7 & & $1.01(0.96,1.07)$ & .58 \\
\hline \multicolumn{7}{|c|}{ 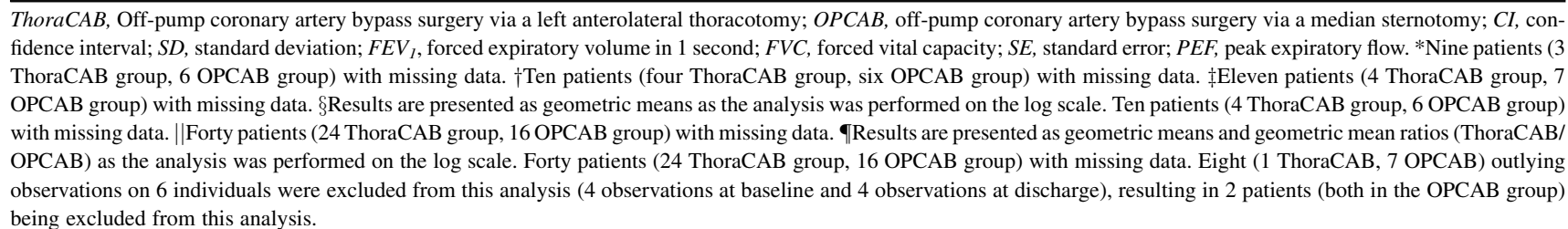 } \\
\hline
\end{tabular}


extent and severity of their coronary disease. This may reflect a learning curve with ThoraCAB. The STET surgeons had all performed more than 30 ThoraCAB procedures before joining the trial and had extensive experience with MICS, ${ }^{3,9}$ but nonetheless their experience with ThoraCAB was significantly less than with OPCAB $(>200$ procedures). Also, ThoraCAB, unlike $\mathrm{OPCAB}$, was not available outside the trial.

\section{CONCLUSIONS}

This is the first RCT of ThoraCAB versus OPCAB. We have demonstrated that the benefits of ThoraCAB — reduced inflammatory response, shorter intubation times, and fewer arrhythmias - are offset by longer operations with fewer grafts, a greater need for postoperative pain relief, worse lung function at discharge, and higher costs. We have also shown that the patients' quality of life at 12 months is similar with the 2 procedures. Our results are at odds with the benefits reported in observational studies; our experience with ThoraCAB is less than with OPCAB and further evaluation is needed before widespread dissemination.

We thank the clinical trial coordinators and research nurses, in particular Dr Lucy Culliford, for managing the trial and collecting trial data; Dr Daphne Kounali and Mrs Kate Bayliss for assisting with the statistical analysis; Dr Giuseppe Aresu, Dr Nalima Shukla, and Ms Sam Passey for the biomarker analyses; and Dr Sally Tomkins for writing the protocol for postoperative pain relief for ThoraCAB patients.

\section{References}

1. Calafiore AM, Giammarco GD, Teodori G, Bosco G, D'Annunzio E, Barsotti A, et al. Left anterior descending coronary artery grafting via left anterior small thoracotomy without cardiopulmonary bypass. Ann Thorac Surg. 1996;61:1658-63; discussion 64-5.

2. Mariani MA, Boonstra PW, Grandjean JG, Peels JO, Monnink SH, den Heijer P, et al. Minimally invasive coronary artery bypass grafting versus coronary angioplasty for isolated type C stenosis of the left anterior descending artery. J Thorac Cardiovasc Surg. 1997;114:434-9.

3. Diegeler A, Thiele H, Falk V, Hambrecht R, Spyrantis N, Sick P, et al. Comparison of stenting with minimally invasive bypass surgery for stenosis of the left anterior descending coronary artery. $N$ Engl J Med. 2002;347:561-6.

4. Reeves BC, Angelini GD, Bryan AJ, Taylor FC, Cripps T, Spyt TJ, et al. A multicentre randomised controlled trial of minimally invasive direct coronary bypass grafting versus percutaneous transluminal coronary angioplasty with stenting for proximal stenosis of the left anterior descending coronary artery. Health Technol Assess. 2004;8:1-56.

5. Angelini GD, Wilde P, Salerno TA, Bosco G, Calafiore AM. Integrated left small thoracotomy and angioplasty for multivessel coronary artery revascularisation. Lancet. 1996;347:757-8.

6. Murphy GJ, Bryan AJ, Angelini GD. Hybrid coronary revascularization in the era of drug-eluting stents. Ann Thorac Surg. 2004;78:1861-7.

7. Shim JH, Jo WM, Chung WJ, Chung JH. Unexpected stent thrombus after minimally invasive direct coronary artery bypass in hybrid re-vascularisation. Eur J Cardiothorac Surg. 2009;36:419-21.

8. Katz MR, Van Praet F, de Canniere D, Murphy D, Siwek L, Seshadri-Kreaden U, et al. Integrated coronary revascularization: percutaneous coronary intervention plus robotic totally endoscopic coronary artery bypass. Circulation. 2006;114(1 Suppl):I473-6.
9. Angelini GD, Taylor FC, Reeves BC, Ascione R. Early and midterm outcome after off-pump and on-pump surgery in Beating Heart Against Cardioplegic Arrest Studies (BHACAS 1 and 2): a pooled analysis of two randomised controlled trials. Lancet. 2002;359:1194-9.

10. Calafiore AM, Di Mauro M, Teodori G, Di Giammarco G, Cirmeni S, Contini M, et al. Impact of aortic manipulation on incidence of cerebrovascular accidents after surgical myocardial revascularization. Ann Thorac Surg. 2002; 73:1387-93.

11. Cheng DC, Bainbridge D, Martin JE, Novick RJ. Does off-pump coronary artery bypass reduce mortality, morbidity, and resource utilization when compared with conventional coronary artery bypass? A meta-analysis of randomized trials. Anesthesiology. 2005;102:188-203.

12. Puskas JD, Williams WH, Mahoney EM, Huber PR, Block PC, Duke PG, et al. Off-pump vs conventional coronary artery bypass grafting: early and 1-year graft patency, cost, and quality-of-life outcomes: a randomized trial. JAMA. 2004;291: 1841-9.

13. Al-Ruzzeh S, George S, Bustami M, Wray J, Ilsley C, Athanasiou T, et al. Effect of off-pump coronary artery bypass surgery on clinical, angiographic, neurocognitive, and quality of life outcomes: randomised controlled trial. BMJ. 2006;332: 1365.

14. Guida MC, Pecora G, Bacalao A, Munoz G, Mendoza P, Rodriguez L. Multivessel revascularization on the beating heart by anterolateral left thoracotomy. Ann Thorac Surg. 2006;81:2142-6.

15. Srivastava SP, Patel KN, Skantharaja R, Barrera R, Nanayakkara D, Srivastava V. Off-pump complete revascularization through a left lateral thoracotomy (ThoraCAB): the first 200 cases. Ann Thorac Surg. 2003;76:46-9.

16. Singh SK, Mishra SK, Kumar D, Yadave RD, Sinha SK. Multivessel total arterial revascularization via left thoracotomy. Asian Cardiovasc Thorac Ann. 2004;12: $30-2$.

17. de Canniere D, Jansens JL, Goldschmidt-Clermont P, Barvais L, Decroly P, Stoupel E. Combination of minimally invasive coronary bypass and percutaneous transluminal coronary angioplasty in the treatment of double-vessel coronary disease: two-year follow-up of a new hybrid procedure compared with "on-pump" double bypass grafting. Am Heart J. 2001;142:563-70.

18. Ascione R, Lloyd CT, Underwood MJ, Lotto AA, Pitsis AA, Angelini GD. Inflammatory response after coronary revascularization with or without cardiopulmonary bypass. Ann Thorac Surg. 2000;69:1198-204.

19. Wilson AP, Treasure T, Sturridge MF, Gruneberg RN. A scoring method (ASEPSIS) for postoperative wound infections for use in clinical trials of antibiotic prophylaxis. Lancet. 1986;1:311-3.

20. Schroter S, Lamping DL. Coronary revascularisation outcome questionnaire (CROQ): development and validation of a new, patient based measure of outcome in coronary bypass surgery and angioplasty. Heart. 2004; 90:1460-6.

21. Sealed Envelope. Sealed Envelop randomisation services Web site. Available at: http://www.sealedenvelope.com. Accessed February 23, 2011.

22. Matros E, Aranki SF, Bayer LR, McGurk S, Neuwalder J, Orgill DP. Reduction in incidence of deep sternal wound infections: random or real? J Thorac Cardiovasc Surg. 2010;139:680-5.

23. National Health Service. NHS reference costs 2008-09. Appendix NSRC1. Available at: http://www.dh.gov.uk/en/Publicationsandstatistics/Publications/ PublicationsPolicyAndGuidance/DH_111591. Accessed February 23, 2011.

24. Al-Ruzzeh S, Epstein D, George S, Bustami M, Wray J, Ilsley C, et al. Economic evaluation of coronary artery bypass grafting surgery with and without cardiopulmonary bypass: cost-effectiveness and quality-adjusted life years in a randomized controlled trial. Artif Organs. 2008;32:891-7.

25. Personal Social Services Research Unit. Unit costs of health and social care 2006, section 7.1. Available at: http://www.pssru.ac.uk/pdf/uc/uc2006/uc2006.pdf. Accessed February 23, 2011.

26. Personal Social Services Research Unit. Unit costs of health and social care 2010, section V. Available at: http://www.pssru.ac.uk/uc/uc2010contents.htm. Accessed February 23, 2011.

27. Akaike H. Information theory and extension of the maximum likelihood principle. In: Petrov BN, Csaki F, eds. Second International Symposium on Information theory. Budapest (Hungary): Akademiai Kiado; 1973:267-81.

28. CONSORT. Baseline data. Available at: http://www.consort-statement.org/ consort-statement/13-19-results/item15_baseline-data/. Accessed February 23, 2011. 


\section{APPENDIX E1}

\section{Primary Outcome-Component Definitions}

Infection was defined as (a) systemic lower respiratory tract infection, comprising (i) systemic inflammatory response syndrome (SIRS) and (ii) antibiotic treatment for suspected or proven infection and (iii) at least one of productive cough, new or progressive infiltrates on chest radiograph, positive sputum culture or declining oxygenation or (b) wound infection defined as an in-hospital ASEPSIS score greater than 20 (each wound assessed separately) ${ }^{19}$ or (c) sepsis that comprised (i) documented culture-positive infection or intravenous antibiotic treatment for suspected infection and (ii) SIRS.

SIRS was defined as 2 or more of the following: (i) temperature $>38^{\circ} \mathrm{C}$ or $<36^{\circ} \mathrm{C}$; (ii) heart rate $>90$ beats/minute; (iii) respiratory rate $<20$ breaths/min or arterial carbon dioxide tension $<32 \mathrm{~mm} \mathrm{Hg}$; (iv) white blood cell count $>12,000 / \mathrm{mm}^{3}$ or $<4000 / \mathrm{mm}^{3}$

Normal routine blood test results and temperature were defined as (a) white blood cell count $\geq 4000 / \mathrm{mm}^{3}$ and $\leq 12,000 / \mathrm{mm}^{3}$ and (b) temperature $\geq 36^{\circ} \mathrm{C}$ and $\leq 38^{\circ} \mathrm{C}$.

Physical fitness was defined as the ability to walk $70 \mathrm{~m}$, having an oxygen saturation on air $\geq 95 \%$, and having had the bowels opened.

\section{Cost Analysis}

National Health Service reference costs for 2008/2009 were used. ${ }^{23}$ Operative and ward costs were not available for $2008 / 2009$, so costs from earlier years ${ }^{24,25}$ inflated to $2008 / 2009$ levels using pay and prices index figures ${ }^{26}$ were used.

\section{Statistical Methods}

For the comparison of pain scores between the OPCAB and ThoraCAB groups, the analysis was adjusted for factors included in the cohort minimization plus the assessment method (visual analog scale or verbal). Also, for the analysis of biomarkers, interactions of surgeon, diabetes, and number of diseased vessels with time were considered.

Time-to-event outcomes were compared using hazard ratios or time ratios (TR), depending on the model used. The model (Cox proportional hazards or parametric accelerated failure time) was chosen on the basis of the validity of the model assumptions and goodness of fit, assessed graphically and using the Akaike information criterion. ${ }^{27}$ Timeto-event curves were constructed using the Kaplan-Meier method. Continuous outcomes were compared using a difference in means, with logarithmic transformations if distributions were skewed. For transformed data, the results were transformed back to the original scale after analysis and the results presented as geometric means, with the treatment difference expressed as a ratio of geometric means. Binary outcomes were compared using odds ratios. Formal statisti- cal comparisons are presented for binary outcomes only if more than 10 patients experienced the outcome (with at least 1 event in each treatment group). For multicategory outcomes, ordinal or multinomial logistic regression was used as appropriate. Categories were combined if fewer than $5 \%$ of patients were in any 1 category across both treatment groups. Repeated measures of continuous outcomes were analyzed using the linear mixed effects methodology, and where the outcome was measured both preoperatively and postoperatively, the preoperative and postoperative values were modeled jointly to avoid the need to exclude or impute values for cases with missing preoperative values. Treatment-by-time interactions were examined where possible, and if the interaction was statistically significant at the $10 \%$ level using a likelihood ratio test, changes in treatment effect with time are described; otherwise, an overall treatment effect is reported.

Missing data in baseline characteristics are indicated by footnotes and did not differ substantially between groups. Missing data for outcomes compared at a single time point were infrequent $(<5 \%)$; for these outcomes, the analyses presented use cases with complete data. The only exceptions to this were the patients' judgment of readiness for discharge and 6-week wound infection (both 9\% missing data), where imputation of the most common categories was used. For longitudinal outcomes, missing data was more common (eg, $25 \%$ of pain scores are missing). For these analyses, variables predictive of missingness were identified and included in the model.

Statistical tests for baseline imbalance were not carried out inasmuch as such hypothesis testing can be misleading. ${ }^{28}$

Mixed models were fitted in SAS version 9.2 (SAS Institute Inc, Cary, NC) and MLwin version 2.1 (Centre for Multilevel Modelling, University of Bristol, United Kingdom). All other analyses were performed using Stata version 11.1 (StataCorp LP, College Station, Tex).

\section{Interim Analysis}

The Data Monitoring and Safety Committee periodically reviewed the safety data and a formal interim analysis of time until fit for discharge, total postoperative hospital stay, and pain scores, which was performed when $50 \%$ of patients had been recruited. The $P$ values reported are not corrected for this interim analysis.

\section{Reasons for Not Receiving the Allocated Treatment}

Patient request (2, one in each group), poor gas exchange (1), severe vascular disease (1), high-risk patient (3), poor left ventricular function (1), and ascending aortic aneurysm (1).

Reasons for conversion to on-pump surgery were hemodynamic instability/ST elevation (6), unknown hemorrhagic 
pericarditis (1), intramyocardial vessels (1), severe coronary calcification (1), ventricular fibrillation before grafting (1), and not recorded (1).

\section{Sensitivity Analyses of Time Until Fit for Discharge}

Five sensitivity analyses were undertaken:

1. Test for different treatment effects at the 2 centers $(P=.71)$

2. Excluding protocol violations (TR, 1.04; $95 \% \mathrm{CI}, 0.94$, $1.15 ; P=.48)$
3. Excluding patients without mobility-related fitness data (TR, 1.01; 95\% CI, 0.91, 1.12; $P=.85$ )

4. Relaxing the assumption of a common baseline hazard for all patients, through stratification by center (TR, $1.03 ; 95 \% \mathrm{CI}, 0.94,1.14 ; P=.51$ )

5. Assessing the impact of possible informative censoring by (i) assuming fitness was observed for all patients (TR, $0.99 ; 95 \%$ CI, $0.91,1.08 ; P=.82$ ) and (ii) assuming all censored times had the longest observed time to fitness (TR, 1.01; 95\% CI, 0.92, 1.12; $P=.78$ ). 
TABLE E1. Expected adverse events by treatment received: Patients who had off-pump surgery

\begin{tabular}{|c|c|c|c|c|c|c|}
\hline & \multicolumn{2}{|c|}{$\begin{array}{c}\text { Surgery via } \\
\text { ThoraCAB }(n=84) \\
\end{array}$} & \multicolumn{2}{|c|}{$\begin{array}{c}\text { Surgery via } \\
\text { OPCAB }(n=89)\end{array}$} & \multicolumn{2}{|c|}{ Overall $(\mathbf{n}=\mathbf{1 7 3})$} \\
\hline & $\mathbf{n}$ & $\%$ & $\mathbf{n}$ & $\%$ & $\mathbf{n}$ & $\%$ \\
\hline PATIENTS WITH 1 OR MORE EXPECTED EVENT & 70 & 83 & 77 & 87 & 147 & 85 \\
\hline \multicolumn{7}{|l|}{ PREDISCHARGE EVENTS } \\
\hline Perioperative MI* & 11 & 13 & 2 & 2 & 13 & 8 \\
\hline New Qs in 2 contiguous leads* & 0 & 0 & 0 & 0 & 0 & 0 \\
\hline Raised troponin I $(>0.5 \mu \mathrm{g} / \mathrm{L})^{*}$ & 11 & 13 & 2 & 2 & 13 & 8 \\
\hline New ST depression $>2 \mathrm{~mm}$ in 2 leads* & 3 & 4 & 1 & 1 & 4 & 2 \\
\hline Cardiac arrest* & $\mathbf{0}$ & $\mathbf{0}$ & $\mathbf{0}$ & $\mathbf{0}$ & $\mathbf{0}$ & $\mathbf{0}$ \\
\hline Hemodynamic support & 34 & 40 & 39 & 44 & 73 & 42 \\
\hline Any inotropes (excluding norepinephrine)* & 6 & 7 & 1 & 4 & 7 & 4 \\
\hline Norepinephrine used* & 17 & 20 & 22 & 25 & 39 & 23 \\
\hline $\mathrm{IABP}^{*}$ & 0 & 0 & 1 & 1 & 1 & 1 \\
\hline Pulmonary artery catheter* & 0 & 0 & 0 & 0 & 0 & 0 \\
\hline Vasodilator & 17 & 20 & 17 & 19 & 34 & 20 \\
\hline Arrhythmias* & 17 & 20 & 31 & 35 & 48 & 28 \\
\hline SVT/AF requiring treatment* & 16 & 19 & 30 & 34 & 46 & 27 \\
\hline $\mathrm{VF} / \mathrm{VT}$ requiring intervention* & 2 & 2 & 2 & 2 & 4 & 2 \\
\hline Pacing $\dagger$ & 0 & 0 & 3 & 3 & 3 & 2 \\
\hline Pulmonary complications* & 11 & 13 & 11 & 13 & 22 & 13 \\
\hline Reintubation and ventilation* & 3 & 4 & 3 & 3 & 6 & 3 \\
\hline Tracheostomy* & 2 & 2 & 0 & 0 & 2 & 1 \\
\hline Mask CPAP* & 10 & 12 & 10 & 11 & 20 & 12 \\
\hline ARDS* & 0 & 0 & 0 & 0 & 0 & 0 \\
\hline Renal complications* (new hemofiltration/dialysis) & $\mathbf{0}$ & $\mathbf{0}$ & $\mathbf{0}$ & $\mathbf{0}$ & $\mathbf{0}$ & $\mathbf{0}$ \\
\hline Infective complications & 67 & 80 & 76 & 85 & 143 & 83 \\
\hline Septicemia* & 1 & 1 & 1 & 1 & 2 & 1 \\
\hline Culture-positive sputum* & 0 & 0 & 2 & 2 & 2 & 1 \\
\hline Productive cough $\ddagger$ & 38 & 45 & 37 & 43 & 75 & 44 \\
\hline Temperature $>38^{\circ} \mathrm{C}$ or $<36^{\circ} \mathrm{C}$ & 9 & 11 & 12 & 13 & 21 & 12 \\
\hline White cell count $>12,000$ or $<4000$ & 46 & 55 & 53 & 60 & 99 & 57 \\
\hline Raised CRP (>100) & 58 & 69 & 68 & 76 & 126 & 73 \\
\hline New/progressive radiographic infiltrates on chest $\mathrm{x}$-ray film & 11 & 13 & 9 & 10 & 20 & 12 \\
\hline Heart rate $>90$ beats/min* & 47 & 56 & 52 & 59 & 99 & 58 \\
\hline Respiratory rate $>20$ breaths $/ \mathrm{min}$ or $\mathrm{PaCO}_{2}<32 \mathrm{~mm} \mathrm{Hg}$ & 49 & 58 & 51 & 57 & 100 & 58 \\
\hline IV antibiotics* & 6 & 7 & 12 & 14 & 18 & 10 \\
\hline Oral antibiotics* & 8 & 10 & 8 & 9 & 16 & 9 \\
\hline GI complications* & 2 & 2 & $\mathbf{1}$ & 1 & 3 & 2 \\
\hline Peptic ulcer/GI bleed/perforation* & 1 & 1 & 1 & 1 & 2 & 1 \\
\hline Pancreatitis* & 0 & 0 & 0 & 0 & 0 & 0 \\
\hline Other (eg, laparotomy, obstruction)* & 1 & 1 & 0 & 0 & 1 & 1 \\
\hline Neurologic complications* & 1 & 1 & 1 & 1 & 2 & 1 \\
\hline Stroke* & 0 & 0 & 0 & 0 & 0 & 0 \\
\hline Coma or confusion state* & 1 & 1 & 1 & 1 & 2 & 1 \\
\hline TIA* & 0 & 0 & 0 & 0 & 0 & 0 \\
\hline Reoperation $\oint$ & 3 & 4 & 1 & 1 & 4 & 2 \\
\hline Death before discharge & 1 & 1 & $\mathbf{0}$ & $\mathbf{0}$ & 1 & 1 \\
\hline \multicolumn{7}{|l|}{ POSTDISCHARGE EVENTS } \\
\hline Possibly related & 2 & 2 & 1 & 1 & 3 & 2 \\
\hline Stroke resulting in readmission and subsequent death & 0 & & 1 & & 1 & \\
\hline \multicolumn{7}{|l|}{ Readmission with ventricular tachycardia; ICD inserted } \\
\hline Further readmissions with ICD problems and arrhythmias & 1 & & 0 & & 1 & \\
\hline Wound infection requiring readmission & 1 & & 0 & & 1 & \\
\hline
\end{tabular}




\begin{tabular}{|c|c|c|c|c|c|c|}
\hline & \multicolumn{2}{|c|}{$\begin{array}{c}\text { Surgery via } \\
\text { ThoraCAB }(n=84)\end{array}$} & \multicolumn{2}{|c|}{$\begin{array}{c}\text { Surgery via } \\
\text { OPCAB }(\mathbf{n}=\mathbf{8 9})\end{array}$} & \multicolumn{2}{|c|}{ Overall $(n=173)$} \\
\hline & $\mathbf{n}$ & $\%$ & $\mathbf{n}$ & $\%$ & $\mathbf{n}$ & $\%$ \\
\hline Probably related & 1 & 1 & $\mathbf{0}$ & $\mathbf{0}$ & 1 & 1 \\
\hline Wound infection requiring readmission & 1 & & 0 & & 1 & \\
\hline Unrelated & $\mathbf{0}$ & $\mathbf{0}$ & 3 & 3 & 3 & 2 \\
\hline \multicolumn{7}{|l|}{ Chest infection/pneumonia requiring readmission } \\
\hline Respiratory failure resulting in death & 0 & & 1 & & 1 & \\
\hline \multicolumn{7}{|l|}{ Readmitted for drainage of large left pleural effusion } \\
\hline Discharged home after $5 \mathrm{~d}$ after removal of drain & 0 & & 1 & & 1 & \\
\hline \multicolumn{7}{|c|}{ Repeat admissions to A\&E with pericardial effusion and left pleural effusion } \\
\hline Undergoing follow-up outpatient appointments with cardiologist & 0 & & 1 & & 1 & \\
\hline Relationship unknown & 2 & 2 & 5 & 6 & 7 & 4 \\
\hline Leg infection & 0 & & 1 & & 1 & \\
\hline Septic leg & 1 & & 0 & & 1 & \\
\hline Arrhythmia & 1 & & 0 & & 1 & \\
\hline Pleural effusion & 0 & & 1 & & 1 & \\
\hline TIA & 0 & & 1 & & 1 & \\
\hline Wound infection $\|$ & 0 & & 1 & & 1 & \\
\hline Sternum infection/not healing & 0 & & 1 & & 1 & \\
\hline
\end{tabular}

Each bold event is composed of the events listed below it. A patient can experience more than 1 of the component events. ThoraCAB, Off-pump coronary artery bypass surgery via a left anterolateral thoracotomy; $O P C A B$, off-pump coronary artery bypass surgery via a median sternotomy; $M I$, myocardial infarction; IABP, intra-aortic balloon pump; $S V T$, supraventricular tachycardia; $A F$, atrial fibrillation; $V F$, ventricular fibrillation; $V T$, ventricular tachycardia; $C P A P$, continuous positive airway pressure; $A R D S$, acute respiratory distress syndrome; $C R P$, C-reactive protein; $\mathrm{Paco}_{2}$, arterial carbon dioxide tension; $I V$, intravenous; $G I$, gastrointestinal; $T I A$, transient ischemic attack; $I C D$, implantable cardioverter defibrillator; A\&E, accident and emergency. *One patient (OPCAB group) with missing data. †Pacing was permanent for 1 patient in the OPCAB group (status unknown for the remaining 2 patients). One patient (OPCAB group) with missing data. $\ddagger$ Two patients (both OPCAB group) with missing data. §All reoperations occurred in the first 24 hours after surgery and were for bleeding. Two patients (both OPCAB group) with missing data. ||Patient admitted twice for this reason. 
TABLE E2. Expected adverse events by treatment received: Patients who had on-pump surgery

\begin{tabular}{|c|c|c|c|c|}
\hline & \multicolumn{2}{|c|}{ Surgery via ThoraCAB $(n=0)$} & \multicolumn{2}{|c|}{ Surgery via OPCAB $(\mathrm{n}=11)$} \\
\hline & $\mathbf{n}$ & $\%$ & $\mathbf{n}$ & $\%$ \\
\hline PATIENTS WITH 1 OR MORE EXPECTED EVENT & & & 7 & 64 \\
\hline \multicolumn{5}{|l|}{ PREDISCHARGE EVENTS } \\
\hline Perioperative MI & & & 2 & 18 \\
\hline New Qs in 2 contiguous leads & & & 1 & \\
\hline Raised troponin $\mathrm{I}(>0.5 \mu \mathrm{g} / \mathrm{L})$ & & & 2 & \\
\hline New ST depression $>2 \mathrm{~mm}$ in 2 leads & & & 0 & \\
\hline Cardiac arrest & & & $\mathbf{0}$ & $\mathbf{0}$ \\
\hline Hemodynamic support & & & 3 & 27 \\
\hline Any inotropes (excluding norepinephrine) & & & 3 & \\
\hline Norepinephrine used & & & 2 & \\
\hline IABP & & & 1 & \\
\hline Pulmonary artery catheter & & & 1 & \\
\hline Vasodilator & & & 0 & \\
\hline Arrhythmias & & & 5 & 45 \\
\hline SVT/AF requiring treatment & & & 5 & \\
\hline $\mathrm{VF} / \mathrm{VT}$ requiring intervention & & & 1 & \\
\hline Pacing & & & 0 & \\
\hline Pulmonary complications & & & $\mathbf{0}$ & $\mathbf{0}$ \\
\hline Reintubation and ventilation & & & 0 & \\
\hline Tracheostomy & & & 0 & \\
\hline Mask CPAP & & & 0 & \\
\hline ARDS & & & 0 & \\
\hline Renal complications (new hemofiltration/dialysis) & & & $\mathbf{0}$ & $\mathbf{0}$ \\
\hline Infective complications & & & 6 & 55 \\
\hline Septicemia & & & 1 & \\
\hline Culture-positive sputum & & & 0 & \\
\hline Productive cough & & & 0 & \\
\hline Temperature $>38^{\circ} \mathrm{C}$ or $<36^{\circ} \mathrm{C}$ & & & 1 & \\
\hline White cell count $>12,000$ or $<4,000$ & & & 6 & \\
\hline Raised CRP $(>100)$ & & & 2 & \\
\hline New/progressive radiographic infiltrates on chest radiograph & & & 0 & \\
\hline Heart rate $>90$ beats $/ \mathrm{min}$ & & & 2 & \\
\hline Respiratory rate $>20$ breaths $/ \mathrm{min}$ or $\mathrm{PaCO}_{2}<32 \mathrm{~mm} \mathrm{Hg}$ & & & 2 & \\
\hline IV antibiotics & & & 1 & \\
\hline Oral antibiotics & & & 0 & \\
\hline GI complications & & & $\mathbf{0}$ & $\mathbf{0}$ \\
\hline Peptic ulcer/GI bleed/perforation & & & 0 & \\
\hline Pancreatitis & & & 0 & \\
\hline Other (eg, laparotomy, obstruction) & & & 0 & \\
\hline Neurologic complications & & & $\mathbf{0}$ & $\mathbf{0}$ \\
\hline Stroke & & & 0 & \\
\hline Coma or confusion state & & & 0 & \\
\hline TIA & & & 0 & \\
\hline Reoperation & & & $\mathbf{0}$ & $\mathbf{0}$ \\
\hline Death before discharge & & & $\mathbf{0}$ & $\mathbf{0}$ \\
\hline \multicolumn{5}{|l|}{ POSTDISCHARGE EVENTS } \\
\hline Relationship unknown & & & 1 & $\mathbf{0}$ \\
\hline Pleural effusion, suspected heart attack & & & 1 & \\
\hline
\end{tabular}

Each bold event is composed of the events listed below it. A patient can experience more than 1 of the component events. ThoraCAB, Off-pump coronary artery bypass surgery via a left anterolateral thoracotomy; $O P C A B$, off-pump coronary artery bypass surgery via a median sternotomy; $M I$, myocardial infarction; IABP, intra-aortic balloon pump; SVT, supraventricular tachycardia; $A F$, atrial fibrillation; $V F$, ventricular fibrillation; $V T$, ventricular tachycardia; $C P A P$, continuous positive airway pressure; $A R D S$, acute respiratory distress syndrome; $C R P$, C-reactive protein; $\mathrm{Paco}_{2}$, arterial carbon dioxide tension; IV, intravenous; $G I$, gastrointestinal; TIA, transient ischemic attack; ICD, implantable cardioverter defibrillator; $A \& E$, accident and emergency. 
TABLE E3. Unexpected adverse events by treatment received

\section{Patients who had off-pump surgery*}

Patients with 1 or more unexpected event

Definitely related

Left heart hernia through thoracotomy wound requiring readmission

Ventricular hernia repair via thoracotomy and sternotomy

Probably related

Hemothorax requiring readmission, clot and type A aortic

dissection, bilateral effusions, $\mathrm{h}$

ematoma in right ventricle, renal failure

Unlikely to be related

Readmission for chest pain and shortness of breath. Investigations could not find likely cause. Discharged after $26 \mathrm{~d}$ after prescription of anxiety drugs

Unrelated

Readmitted for lead replacement to ICD

Readmission owing to pain at ICD site

Delayed reaction to antibiotics causing rash and pyrexia

Relationship unknown

Chest pain-not cardiac

Hernia

Pleurisy

Sternum-wiring/clip problems

Chest pain

ECG, 24 h

Shortness of breath, chest radiographs $\dagger$

Pneumonia

Chest pain, blood pressure monitor for $24 \mathrm{~h} \dagger$

Thrombosis/embolism

Irregular heartbeat

\begin{tabular}{ccc}
$\begin{array}{c}\text { Surgery via } \\
\text { ThoraCAB }(\mathbf{n}=\mathbf{8 4})\end{array}$ & $\begin{array}{c}\text { Surgery via } \\
\text { OPCAB }(\mathbf{n}=\mathbf{8 9})\end{array}$ & Overall $(\mathbf{n}=\mathbf{1 7 3})$ \\
\hline $10(12 \%)$ & $7(8 \%)$ & $17(10 \%)$ \\
1 & 0 & 1 \\
1 & 0 & 1 \\
1 & 0 & 1 \\
1 & 0 & 1 \\
1 & & $\mathbf{1}$ \\
1 & $\mathbf{0}$ & 1
\end{tabular}

Thora $C A B$, Off-pump coronary artery bypass surgery via a left anterolateral thoracotomy; $O P C A B$, off-pump coronary artery bypass surgery via a median sternotomy; $I C D$, implantable cardioverter defibrillator; $E C G$, electrocardiogram. *There were no events in patients who had on-pump surgery (n $=11)$. $\nmid$ Each of these patients was admitted twice for the same reason.

TABLE E4. Pain relief —additional information (ThoraCAB patients only)

\begin{tabular}{lcr}
\hline & \multicolumn{2}{c}{$\begin{array}{c}\text { Randomized to } \\
\text { ThoraCAB (n=91) }\end{array}$} \\
\cline { 2 - 2 } & \multicolumn{1}{c}{$\mathbf{n}$} \\
\hline PV block volume in first 24 h & & \\
Median (IQR) mL & $234(90,250)$ \\
PV block volume overall & & 0 \\
Median (IQR) mL & $360(95,520)$ & 1 \\
PV block complications & 0 & 1 \\
Cardiac arrest* & 1 & 11 \\
Convulsions without cardiac arrest* & 1 & 9 \\
Persistent hypotension* & & 0 \\
PV block failure $\dagger$ &
\end{tabular}

Thora $C A B$, Off-pump coronary artery bypass surgery via a left anterolateral thoracotomy; $P V$, paravertebral; $I Q R$, interquartile range. *Twenty-two patients with missing data. $\dagger$ Of the patients with PV block failure, 6 had at least one bolus, 1 had an intercostal block, 4 had nurse-administered intravenous morphine, and none had diclofenac, intravenous ketamine, clonidine, or any other pain relief. Eleven patients have missing data. 
TABLE E5. Biochemical inflammatory markers

\begin{tabular}{|c|c|c|c|c|c|c|c|}
\hline \multirow{2}{*}{$\begin{array}{l}\text { Variable (log-scale) } \\
\text { Baseline }\end{array}$} & \multicolumn{2}{|c|}{$\begin{array}{c}\text { Randomized to } \\
\text { ThoraCAB }(n=30)\end{array}$} & \multicolumn{2}{|c|}{$\begin{array}{c}\text { Randomized to } \\
\text { OPCAB }(n=27)\end{array}$} & \multirow[t]{2}{*}{$\begin{array}{c}\text { Mean difference } \\
\text { (ThoraCAB-OPCAB) }(95 \% \text { CI) }\end{array}$} & \multirow[t]{2}{*}{ GMR $(95 \%$ CI $)$} & \multirow[t]{2}{*}{$\begin{array}{c}P \\
\text { value }\end{array}$} \\
\hline & Mean & SD & Mean & SD & & & \\
\hline IL-6 $(\mathrm{pg} / \mathrm{mL})^{*}$ & 1.17 & 0.64 & 1.35 & 0.93 & & & \\
\hline $\mathrm{IL}-8(\mathrm{pg} / \mathrm{mL}) \dagger$ & 1.96 & 0.51 & 2.01 & 0.46 & & & \\
\hline $\mathrm{IL}-10(\mathrm{pg} / \mathrm{mL}) \ddagger$ & 2.14 & 0.52 & 2.10 & 0.49 & & & \\
\hline $\mathrm{C} 3 \mathrm{a}(\mathrm{ng} / \mathrm{mL}) \S$ & 7.74 & 0.30 & 7.52 & 0.50 & & & \\
\hline $\mathrm{C} 5 \mathrm{a}(\mathrm{ng} / \mathrm{mL}) \|$ & 2.76 & 0.40 & 2.62 & 0.42 & & & \\
\hline After intervention & Mean & SE & Mean & SE & & & \\
\hline IL-6 (pg/mL) & $(\mathrm{n}=29)$ & & $(\mathrm{n}=27)$ & & & & \\
\hline End of surgery 9 & 5.29 & 0.24 & 5.10 & 0.25 & $0.19(-0.22,0.59)$ & $1.21(0.80,1.80)$ & \\
\hline Four hours after surgery\# & 5.66 & 0.19 & 6.00 & 0.19 & $-0.33(-0.64,-0.01)$ & $0.72(0.53,0.99)$ & \\
\hline Twelve hours after surgery** & 5.79 & 0.25 & 5.85 & 0.25 & $-0.06(-0.49,0.38)$ & $0.94(0.61,1.46)$ & \\
\hline Twenty-four hours after surgery $\dagger \dagger$ & 5.80 & 0.22 & 5.84 & 0.22 & $-0.04(-0.41,0.33)$ & $0.96(0.66,1.39)$ & \\
\hline Test for treatment time interaction & & & & & & & .013 \\
\hline IL-8 (pg/mL) & $(\mathrm{n}=29)$ & & $(\mathrm{n}=27)$ & & & & \\
\hline End of surgery** & 2.91 & 0.17 & 3.08 & 0.17 & & & \\
\hline Four hours after surgery $\ddagger \ddagger$ & 3.34 & 0.15 & 3.52 & 0.15 & & & \\
\hline Twelve hours after surgery** & 3.61 & 0.17 & 3.62 & 0.17 & & & \\
\hline Twenty-four hours after surgery\# & 3.37 & 0.17 & 3.64 & 0.17 & & & \\
\hline Test for treatment time interaction & & & & & & & .12 \\
\hline Overall estimate of treatment effect & & & & & $-0.19(-0.38,-0.004)$ & $0.82(0.68,0.99)$ & .044 \\
\hline IL-10 (pg/mL) & $(\mathrm{n}=26)$ & & $(\mathrm{n}=25)$ & & & & \\
\hline End of surgery** & 2.66 & 0.27 & 2.34 & 0.28 & & & \\
\hline Four hours after surgery $\ddagger \ddagger$ & 2.86 & 0.23 & 2.72 & 0.24 & & & \\
\hline Twelve hours after surgery** & 2.97 & 0.22 & 3.09 & 0.23 & & & \\
\hline Twenty-four hours after surgery\# & 2.98 & 0.26 & 3.07 & 0.27 & & & \\
\hline Test for treatment time interaction & & & & & & & .23 \\
\hline Overall estimate of treatment effect & & & & & $0.04(-0.22,0.30)$ & $1.04(0.80,1.35)$ & .77 \\
\hline C3a (ng/mL) & $(\mathrm{n}=30)$ & & $(\mathrm{n}=27)$ & & & & \\
\hline End of surgery** & 7.74 & 0.12 & 7.61 & 0.13 & $0.13(-0.08,0.33)$ & $1.14(0.92,1.39)$ & \\
\hline Four hours after surgery $\ddagger \ddagger$ & 7.52 & 0.12 & 7.41 & 0.12 & $0.11(-0.10,0.31)$ & $1.12(0.90,1.36)$ & \\
\hline Twelve hours after surgery** & 7.40 & 0.12 & 7.56 & 0.12 & $-0.17(-0.35,0.01)$ & $0.84(0.70,1.01)$ & \\
\hline Twenty-four hours after surgery $\|$ & 7.62 & 0.13 & 7.75 & 0.13 & $-0.13(-0.34,0.08)$ & $0.87(0.71,1.08)$ & \\
\hline Test for treatment time interaction & & & & & & & .007 \\
\hline C5a (ng/mL) & $(\mathrm{n}=30)$ & & $(\mathrm{n}=27)$ & & & & \\
\hline End of surgery $\|$ & 2.64 & 0.12 & 2.58 & 0.13 & & & \\
\hline Four hours after surgery & 2.85 & 0.11 & 2.73 & 0.12 & & & \\
\hline Twelve hours after surgery & 2.90 & 0.12 & 2.81 & 0.12 & & & \\
\hline Twenty-four hours after surgery & 3.10 & 0.13 & 3.02 & 0.13 & & & \\
\hline Test for treatment time interaction & & & & & & & .70 \\
\hline Overall estimate of treatment effect & & & & & $0.09(-0.03,0.20)$ & $1.09(0.97,1.22)$ & .12 \\
\hline
\end{tabular}


TABLE E6. Hospital resource use and costs

\begin{tabular}{|c|c|c|c|c|}
\hline & Randomized to ThoraCAB $(n=91)$ : GM & Randomized to OPCAB $(n=93):$ GM & Effect $(95 \%$ CI) & $P$ value \\
\hline Total cost* & $£ 5079$ & $£ 4566$ & GMR $1.10(1.02,1.18)$ & .007 \\
\hline Operation cost & $£ 2363$ & $£ 1987$ & & \\
\hline Reoperation cost $\dagger$ & $£ 869$ & $£ 0$ & & \\
\hline Intensive care unit cost & $£ 1411$ & $£ 1430$ & & \\
\hline High dependency unit cost & $£ 831$ & $£ 613$ & & \\
\hline Ward cost & $£ 293$ & $£ 381$ & & \\
\hline Readmission cost $\ddagger$ & $£ 888$ & $£ 428$ & & \\
\hline
\end{tabular}

ThoraCAB, Off-pump coronary artery bypass surgery via a left anterolateral thoracotomy; $O P C A B$, off-pump coronary artery bypass surgery via a median sternotomy; $C I$, confidence interval; $G M$, geometric mean; GMR, geometric mean ratio. *Three outliers were excluded from model ( 2 ThoraCAB group, 1 OPCAB group). $\dagger$ Four patients had a reoperation (all ThoraCAB group). $\ddagger$ Twenty three patients were readmitted in the first postoperative year (10 ThoraCAB group, 13 OPCAB group). 
TABLE E7. Quality of life scores (Coronary Revascularization Outcome Questionnaire)

\begin{tabular}{|c|c|c|c|c|c|c|c|c|}
\hline \multirow[b]{2}{*}{ Baseline } & \multicolumn{3}{|c|}{ Randomized to ThoraCAB $(n=66)$} & \multicolumn{3}{|c|}{ Randomized to OPCAB $(n=66)$} & \multirow[t]{2}{*}{ Effect $(95 \%$ CI $)$} & \multirow[t]{2}{*}{$P$ value } \\
\hline & $\mathrm{n}$ & Mean & SD & $\mathrm{n}$ & Mean & SD & & \\
\hline Core total & 62 & 49.7 & 6.12 & 63 & 50.2 & 6.73 & & \\
\hline Symptoms & 63 & 74.5 & 19.6 & 63 & 73.8 & 21.7 & & \\
\hline Physical functioning & 62 & 72.9 & 26.1 & 63 & 69.0 & 28.3 & & \\
\hline Psychosocial functioning & 62 & 65.7 & 21.8 & 63 & 70.0 & 23.9 & & \\
\hline Cognitive functioning & 62 & 79.5 & 23.0 & 63 & 82.9 & 25.2 & & \\
\hline Follow-up & $\mathrm{n}$ & Mean & SE & & Mean & SE & & \\
\hline \multicolumn{9}{|l|}{ Core total* } \\
\hline Three months & 53 & 48.3 & 1.13 & 50 & 48.9 & 1.17 & & \\
\hline Twelve months & 56 & 48.7 & 1.14 & 54 & 49.1 & 1.18 & & \\
\hline Test for treatment time interaction & & & & & & & & .81 \\
\hline Overall estimate of treatment effect & & & & & & & $-0.47(-1.94,0.99)$ & .52 \\
\hline \multicolumn{9}{|l|}{ Symptoms $\dagger$} \\
\hline Three months & 53 & 91.5 & 1.83 & 50 & 92.1 & 1.93 & & \\
\hline Twelve months & 56 & 95.0 & 1.48 & 54 & 96.9 & 1.63 & & \\
\hline Test for treatment time interaction & & & & & & & & .51 \\
\hline Overall estimate of treatment effect & & & & & & & $-1.64(-3.88,0.59)$ & .15 \\
\hline \multicolumn{9}{|l|}{ Physical functioning $\ddagger$} \\
\hline Three months & 53 & 84.6 & 3.96 & 50 & 87.3 & 4.17 & & \\
\hline Twelve months & 55 & 94.5 & 3.65 & 54 & 91.6 & 3.89 & & \\
\hline Test for treatment time interaction & & & & & & & & .12 \\
\hline Overall estimate of treatment effect & & & & & & & $1.26(-3.98,6.51)$ & .63 \\
\hline \multicolumn{9}{|l|}{ Psychosocial functioning $\S$} \\
\hline Three months & 53 & 74.0 & 3.18 & 50 & 74.7 & 3.30 & & \\
\hline Twelve months & 56 & 84.8 & 2.58 & 54 & 85.7 & 2.81 & & \\
\hline Test for treatment time interaction & & & & & & & & .95 \\
\hline Overall estimate of treatment effect & & & & & & & $-0.83(-4.63,2.97)$ & .66 \\
\hline \multicolumn{9}{|l|}{ Cognitive functioning $\|$} \\
\hline Three months & 53 & 81.7 & 3.43 & 50 & 81.6 & 3.59 & & \\
\hline Twelve months & 54 & 87.9 & 2.93 & 54 & 89.2 & 3.19 & & \\
\hline Test for treatment time interaction & & & & & & & & .67 \\
\hline Overall estimate of treatment effect & & & & & & & $-0.96(-5.25,3.32)$ & .65 \\
\hline \multicolumn{9}{|l|}{ Satisfaction $\uparrow$} \\
\hline Three months & 51 & 81.6 & 3.05 & 50 & 82.9 & 3.32 & & \\
\hline Twelve months & 55 & 82.7 & 3.07 & 54 & 87.7 & 3.38 & & \\
\hline Test for treatment time interaction & & & & & & & & .15 \\
\hline Overall estimate of treatment effect & & & & & & & $-3.21(-8.19,1.77)$ & .20 \\
\hline \multicolumn{9}{|l|}{ Adverse events\# } \\
\hline Three months & 51 & 80.4 & 2.37 & 50 & 81.5 & 2.58 & & \\
\hline Twelve months & 55 & 89.4 & 2.40 & 54 & 88.7 & 2.62 & & \\
\hline Test for treatment time interaction & & & & & & & & .40 \\
\hline Overall estimate of treatment effect & & & & & & & $-0.17(-4.01,3.67)$ & .93 \\
\hline
\end{tabular}

The number of observations varies slightly between different scores owing to insufficient data being available to calculate scores for a small number of observations. ThoraCAB, Off-pump coronary artery bypass surgery via a left anterolateral thoracotomy; $O P C A B$, off-pump coronary artery bypass surgery via a median sternotomy; $C I$, confidence interval; $S D$, standard deviation; $S E$, standard error. *Three outliers were excluded for 12-month scores (1 in ThoraCAB group, 2 in OPCAB group). A compound symmetry covariance pattern was used. †One outlier was excluded for 3-month scores (ThoraCAB group); 4 outliers were excluded for 12 -month scores (1 in ThoraCAB group, 3 in OPCAB group). A general (unstructured) covariance pattern was used. $\ddagger$ No outliers were excluded. A general (unstructured) covariance pattern was used. $\S$ Two outliers were excluded for $12-$ month scores (1 in ThoraCAB group, 1 in OPCAB group). A general (unstructured) covariance pattern was used. ||Two outliers were excluded for 12-month scores (both in ThoraCAB group). A general (unstructured) covariance pattern was used. $\uparrow$ Two outliers were excluded for 3-month scores (both in ThoraCAB group); 4 outliers were excluded for 12 -month scores ( 2 in ThoraCAB group, 2 in OPCAB group). A compound symmetry covariance pattern was used. \#Two outliers were excluded for 12 -month scores (both in ThoraCAB group). A compound symmetry covariance pattern was used. 